\title{
A comprehensive laboratory study on the immersion freezing behavior of illite NX particles: a comparison of 17 ice nucleation measurement techniques
}

N. Hiranuma et al.

Correspondence to: N. Hiranuma (seong.moon@ kit.edu) 


\section{S1. Supplementary Methods}

This supplementary information provides additional details for the measurement techniques of immersion freezing of illite NX particles with S1.1. suspension techniques and S1.2. dry-dispersed particle measurement techniques (both in alphabetical order as in Table 1). The discussions of measurement uncertainties of temperature and $n_{s}$ for each measurement technique are also provided. We note that the uncertainty in frozen fraction $(\alpha)$ used in calculating $n_{s}$ may not be adequate, since the sensitivity of $\Delta \alpha$ (an increase or a decrease in frozen fraction) is much higher at high temperatures which unexceptionally coincide with a low fraction of frozen illite NX.

\section{S1.1. Suspension techniques}

\section{Bielefeld Ice Nucleation ARraY (BINARY)}

The BINARY setup is an optical freezing apparatus that makes use of the change in droplet brightness during freezing for the automated and simultaneous detection of ice nucleation in 36 microliter-sized droplets. The droplets are positioned on a hydrophobic glass slide that rests on top of a Peltier cooling stage (Linkam LTS 120). The 36 droplets are separated from each other by a polydimethylsiloxane (PDMS) spacer in order to prevent a Wegener-Bergeron-Findeisen process. For a particular illite NX concentration $(0.1,0.5,2,5$ and $10 \mathrm{mg} \mathrm{mL}^{-1}$ based on the amount of suspended mass of illite $\mathrm{NX}$ sample per $\mathrm{H}_{2} \mathrm{O}$ volume) at least 3 experiments with 36 drops each were conducted, resulting in a minimum of at least 108 freezing events at each concentration. The droplet temperature was calibrated based on phase transition temperatures of several compounds over the range from 0 to $-40{ }^{\circ} \mathrm{C}$ and for rates between 0.1 and $10{ }^{\circ} \mathrm{C} \mathrm{min}^{-1}$. Details of the setup and its temperature calibration are presented elsewhere (Budke and Koop, 2014). In addition to this temperature calibration no further corrections were made to the dataset of observed individual droplet freezing temperatures. However, if any droplet freezing temperatures of a particular concentration were below $-25^{\circ} \mathrm{C}$, this concentration was excluded from the analysis. At these temperatures, the derived $n_{s}$ for different illite NX mass concentrations deviate from each other, indicating 
that ice nucleation in these droplets was not induced by illite NX particles, but rather by icenucleating impurities contained in the water. This lower temperature limit is also in agreement with the observed 25 th percentile freezing temperature value of about $-26{ }^{\circ} \mathrm{C}$ for pure water samples. Additionally, if at a specific temperature less than $1 \%$ of the freezing events in a concentration series occur, the corresponding data point was also excluded.

Experimental uncertainties: The spread of experimentally found transition temperatures in the calibration indicates a quartiles-based error of $\pm 0.3{ }^{\circ} \mathrm{C}$. Assuming $10 \%$ errors in the mass concentration, the droplet volume, and the frozen fraction an error of about $20 \%$ is associated to the active site density per mass based on Gaussian error calculation. The maximal error is $35 \%$. For the active site density per surface area an additional error has to be included due to the uncertainty in the specific surface area.

\section{Colorado State University Ice Spectrometer (CSU-IS)}

An immersion-freezing method was used to obtain INP temperature spectra for NXillite clay, both when in bulk suspension and for size-selected particles.

For the bulk clay, a $0.5 \mathrm{wt} \%$ suspension was made in $10 \mathrm{mM}$ sodium phosphate buffer (at $p H 8.7$ to match the $p H$ of the sample and to prevent flocculation, and filtered through a $0.02 \mu \mathrm{m}$ Anotop syringe filter (Whatman)) and mixed by tumbling end-over-end at 1 cycle $\mathrm{s}^{-1}$ for 30 min (Cole-Palmer, Roto-Torque). Measures of INP were made on this suspension and on a series of 20 -fold dilutions to $3.1 \times 10^{-6} \mathrm{wt} \%$ in the same buffer.

Polydisperse NX-illite particles were generated for size selection using the simple flask generator as described in Tobo et al. (2014). For collection of size-selected particles, several grams of dust were placed in a $250 \mathrm{~mL}$ conical flask, and dust released by blowing nitrogen in at the base base $\left(\sim 2 \mathrm{~L} \mathrm{~min}^{-1}\right)$ while agitating the flask in an ultrasonic bath. The particle stream was passed through a dilution tank $\left(\mathrm{N}_{2}\right.$ flow rate into the tank $\left.\sim 5 \mathrm{~L} \mathrm{~min}^{-1}\right)$ and then through a ${ }^{210} \mathrm{Po}$ neutralizer before size selection of particles with a mobility diameter of $500 \mathrm{~nm}$ in a DMA (TSI Inc., Model 3081; sheath flow: $4.5 \mathrm{~L} \mathrm{~min}^{-1}$, sample flow: $1.8 \mathrm{~L}$ $\min ^{-1}$ ). This stream was then divided, with $0.3 \mathrm{~L} \mathrm{~min}^{-1}$ passed to a condensation particle counter (CPC, TSI Inc., Model 3010) and 1.50 $\mathrm{L} \mathrm{min}^{-1}$ drawn through a $47 \mathrm{~mm}$ diameter inline aluminum filter holder (Pall) fitted with a $0.2 \mu \mathrm{m}$-diameter-pore Nuclepore track-etched polycarbonate membrane (Whatman). Concentration of $500 \mathrm{~nm}$ particles was maintained at around 1,500 $\mathrm{cc}^{-1}$ and flow was continued until 127 million particles were collected. Filters and dissembled filter holders had been pre-cleaned, separately, by soaking in $10 \% \mathrm{H}_{2} \mathrm{O}_{2}$ for 
10 and $60 \mathrm{~min}$, respectively, followed by three rinses in deionized water $(18 \mathrm{M} \Omega \mathrm{cm}$ and 0.2 $\mu \mathrm{m}$-diameter-pore filtered). Filters were dried on foil in a particle-free, laminar flow cabinet, as were filter holder components after excess water was removed with a gas duster.

After particle collection, the filter was transferred to a sterile, $50 \mathrm{~mL}$ Falcon polypropylene tube (Corning Life Sciences), $5.0 \mathrm{~mL}$ of $0.2 \mu \mathrm{m}$-pore-diameter-filtered deionized water added (which contained 1-3 INP $\mathrm{mL}^{-1}$ at $-23{ }^{\circ} \mathrm{C}$ ), and particles re-suspended by tumbling for $30 \mathrm{~min}$ on the rotator. Measures of INP were made on this suspension and on a 20 -fold dilution.

To obtain INP temperature spectra, suspensions were first aliquoted into sterile, 96well polypropylene polymerase chain reaction (PCR) trays (Life Science Products Inc.) in a laminar flow cabinet. For each dilution, 32 aliquots of $60 \mu \mathrm{L}$ were dispensed. Trays were capped with polystyrene lids (Nunc microwell plates, Thermo Fisher Scientific Inc.) and transferred to CSU-IS.

The IS was constructed using two 96-well aluminum incubation blocks for PCR plates (VWR) placed end-to-end and encased on their sides and base by cold plates (Lytron). A ULT-80 low temperature bath (Thermo Neslab) circulating SYLTHERM XLT heat transfer fluid (Dow Corning Corporation) was used for cooling. PCR plates were placed in the blocks, the device covered with a plexiglass window and the headspace purged with $1.2 \mathrm{~L} \mathrm{~min}^{-1}$ of filtered (HEPA-CAP, Whatman) nitrogen. Temperature was then lowered at $0.33{ }^{\circ} \mathrm{C} \mathrm{min}^{-1}$, measured using a thermistor verification probe (Bio-Rad, Hercules, CA, VPT-0300) inserted into a side well. The number of frozen wells were counted at 0.5 or $1{ }^{\circ} \mathrm{C}$ degree intervals, and cumulative numbers of INP $\mathrm{mL}^{-1}$ suspension estimated using the formula $\ln (f) / V$, where $f$ is the proportion of droplets not frozen and $V$ is the volume of each aliquot $(\operatorname{Vali}, 1971)$. This was converted to INP g $\mathrm{g}^{-1}$ illite and thence to INP $\mathrm{m}^{-2}$ illite assuming a surface area of $124 \mathrm{~m}^{2}$ $\mathrm{g}^{-1}$ dust. For size-selected particles, mass was calculated assuming particles were spherical and had a density of $2.65 \mathrm{~g} \mathrm{~cm}^{-3}$.

Experimental uncertainties: The temperature uncertainty in the CSU-IS technique is $\pm 0.2{ }^{\circ} \mathrm{C}$ (a combination of the uncertainty in the probe and the temperature variation across the blocks due to gradients in cooling). Binomial sampling confidence intervals (95\%) were derived using as recommended by Agresti and Coull (formula number 2, 1998). Their ranges varied according to the proportion of wells frozen. For a single well frozen out of 32 aliquots, the $95 \%$ confidence interval ranged from $18 \%$ to $540 \%$ of the estimated $n_{s}$ value, while for $31 / 32$ wells frozen it was $53-149 \%$ of the $n_{s}$ value. 


\section{Leeds Nucleation by Immersed Particles Instrument (Leeds-NIPI)}

Picoliter (pL)-NIPI: the experimental approach employed to study freezing by illite NX particles in droplets 10's $\mu \mathrm{m}$ in diameter has been described in detail by Broadley et al. (2012). This instrument has been used in a number of studies of hetereogeneus ice nucleation (Atkinson et al., 2013; Murray et al., 2011; O'Sullivan et al., 2014). Briefly, droplets of dust suspension are generated using a nebuliser and allowed to settle onto a hydrophobic coated glass slide. The droplets are sealed in oil and then transferred to a microscope cold stage where they are cooled at a controlled rate. The droplet freezing temperatures are recorded using a camera coupled to the microscope.

Microliter $(\mu \mathrm{L})$-NIPI: This more recently developed technique makes use of larger droplets $(\sim 1 \mathrm{~mm})$ which thereforecontain a greater surface area of dust for a constant dust concentration. The $\mu \mathrm{L}-\mathrm{NIPI}$ is sensitive to smaller values of $n_{\mathrm{s}}$ than the pL-NIPI. This instrument is described by Atkinson et al. (2013), O'Sullivan et al. (2014) and also used by Herbert et al. (2014) for heterogeneous ice nucleation studies. It has not previously been used for illite NX particles. Briefly, experiments involve pippetting $1 \mu \mathrm{L}$ volume droplets of suspension onto a hydrophobic glass slide positioned on a cold stage. The cold stage is cooled by a stirling engine (Grant-Asymptote EF600) and droplet freezing is recorded using a digital camera. Values of $n_{s}$ have been extended to much higher temperatures using the $\mu \mathrm{L}$ NIPI.

The recorded images of droplets freezing for both NIPI experiments are analysed in order to determine the freezing temperature of each droplet. For the pL-NIPI the size of each droplet is also recorded. In the $\mu$ L-NIPI experiments droplets are of a uniform size since they were pipetted onto the surface.

Experimental uncertainties: To calculate error in $n_{s}$ the Leeds-NIPI measurement, errors from the BET surface area, the weights used to make up suspensions, dust density and estimated pipetting error to calculate an error in the amount of IN surface area per droplet were propagated. The resulting error for $0.1 \mathrm{wt} \%$ and $1 \mathrm{wt} \%$ suspension was $\pm 18.9 \%$ and \pm $10.8 \%$ in $n_{s}$, respectively. The temperature error was calculated by taking the random error of the thermocouple used to measure temperature in a cold stage and propagated this with the melting point range observed for water. This resulted in a maximum error of less than \pm 0.4 ${ }^{\circ} \mathrm{C}$. 


\section{Mainz Acoustic Levitator (M-AL)}

Inside the acoustic levitator (type APOS BA 10 from TEC59) a standing ultrasonic wave is produced by interference where drops can be levitated at the nodes. It is installed inside a walk-in cold chamber where the setup includes the acoustic levitator, a platinumresistor thermometer Pt100 to measure the ambient temperature, a digital video camera to determine the drop sizes, and an infra-red thermometer to directly and contact-free measure the temperature of the freezing drops. These measurements require a circular spot of approximately $1 \mathrm{~mm}$ in diameter and, therefore, the investigated drops had sizes of $2 \pm 0.2$ $\mathrm{mm}$ in diameter. Because of their rather large volume and missing ventilated heat transfer the levitated drops cool down rather slowly while exchanging heat with the ambient air in the cold chamber. This results in a non-linear cooling rate. During the experiments with illite-NX, the temperature of pure water drops developed as follows (Diehl et al., 2014):

$$
T_{\text {drop }}(T)=-27.050{ }^{\circ} \mathrm{C}+27.082{ }^{\circ} \mathrm{C} \exp \left(-\frac{t}{16.374}\right)
$$

where $T_{\text {drop }}(t) i s$ the drop surface temperature, $t$ the time. Individual drops containing polydisperse illite NX particles were levitated one after another and cooled down according to Eqn. S1. The transition from the liquid to the ice phase was clearly defined by a sudden increase of the drop temperature (because of the release of latent heat) recorded from the infra-red thermometer (Diehl et al., 2014). For each particle concentration, approximately 100 drops were observed until they froze and the freezing temperatures, i.e. the lowest drop temperatures were recorded with a measuring error of $\pm 0.7 \mathrm{~K}$. Afterwards, for temperature steps of $1 \mathrm{~K}$ the fractions of frozen drops were counted.

Experimental uncertainties: The uncertainties for $T$ and $n_{s}$ are $\pm 0.7{ }^{\circ} \mathrm{C}$ and $\pm 30 \%$, respectively. The $n_{s}$ uncertainty includes errors of the frozen fractions of drops, the specific particle surface area, the particle masses per drop, and the drop sizes.

\section{Mainz vertical Wind Tunnel (M-WT)}

In the Mainz vertical wind tunnel drops are freely floated at their terminal velocities in an air stream. Thus, ventilation and heat transfer are similar to the situation as in the real atmosphere. The wind speed is uniformly distributed around the entire cross section area up to 
the boundary layer at the tunnel walls. This ensures that drops float in a stable fashion in the observation section of the tunnel (Szakáll et al., 2009; Diehl et al., 2011). The drop size was determined from the recorded wind speed in the tunnel as it must be equal to the terminal velocity of the drop to keep the drop floating in the observation section. The drop temperature was calculated afterwards from the ambient temperature in the wind tunnel and the dew point with an estimated error of $\pm 1 \mathrm{~K}$. Drop sizes of $680 \pm 60 \mu \mathrm{m}$ in diameter were selected because the onset of freezing was determined by direct observation (Diehl et al., 2014). The experiments were performed at constant ambient temperatures, i.e., the wind tunnel was precooled to certain temperatures in steps of $1 \mathrm{~K}$. The adaption time of the drops, i.e., the time after which the drop temperature was equal to the ambient temperature was 4 to $5 \mathrm{~s}$ (Diehl et al., 2014). Individual drops containing polydisperse illite NX particles were observed for approximately 30 to $40 \mathrm{~s}$. 50 drops were investigated per temperature interval and particle concentration. Afterwards, the fractions of frozen drops were counted for a total observation time of $30 \mathrm{~s}$.

Experimental uncertainties: The uncertainties for $T$ and $n_{s}$ are $\pm 1{ }^{\circ} \mathrm{C}$ and $\pm 35 \%$, respectively. Similar to M-AL, the $n_{s}$ uncertainty of M-WT includes errors of the frozen fractions of drops, the specific particle surface area, the particle masses per drop, and the drop sizes.

\section{North Carolina State cold stage (NC State-CS)}

The design of the NC State cold stage-supported droplet freezing assay (NC State-CS for brevity) and data reduction technique is described in detail in Wright and Petters (2013) and Hader et al. (2014). For the experiments reported here, aqueous suspensions ranging from 0.0001 to $1.0 \mathrm{wt} \%$ of dry illite $\mathrm{NX}$ powder and $(18.2 \mathrm{M} \Omega \mathrm{cm}$ resistivity) were prepared. Droplet populations of two distinct size ranges were investigated. Picodrops were generated by mixing a $15 \mu \mathrm{L}$ aliquot of bulk suspension with squalene and emulsifying the hydrocarbonwater mixture using a vortex mixer. The emulsion was poured into an aluminum dish holding a hydrophobic glass slide. This resulted in between 400 and 800 usable droplets per experiment with a typical diameter $D \sim 85 \mu \mathrm{m}$. Nanodrops were generated by manually placing drops with a syringe needle tip on a squalene covered glass slide and letting the drops settle to the squalene-glass interface. This resulted in $\sim 80$ droplets per experiment with a typical diameter $D \sim 660 \mu \mathrm{m}$. For all experiments the aluminum dish was cooled at a constant rate of $1^{\circ} \mathrm{C} \mathrm{min}^{-1}$ and the fraction of unfrozen drops was recorded using a microscope in 
increments of $\Delta T=0.17^{\circ} \mathrm{C}$ resolution. To account for slightly higher temperatures of the squalene relative to the glass slide, a temperature calibration was applied to the nanodrop data (Hader et al., 2014). The resulting fraction of droplets frozen versus temperature data were inverted to find the concentration of INPs using the method of Vali (1971):

$$
c_{\mathrm{IN}}(T)=-\frac{\ln \left(f_{\text {unfrozen }}\right)}{V_{\text {drop }}}
$$

where $c_{\mathrm{IN}}(T)$ is the concentration of INPs per unit volume of water ( $\mathrm{m}^{-3}$ water), $f_{\text {unfrozen }}$ is the fraction of unfrozen drops at each particular temperature, and $V_{\text {drop }}$ is the median drop volume of the population. To minimize sample heterogeneity, only droplets with $78 \mu \mathrm{m}<D<102 \mu \mathrm{m}$ were included in the calculation of $c_{\mathbb{I N}}(T)$ for picodrops. No restriction was applied to the nanodrops. Furthermore, the warmest two percent of data was removed after the calculation of $c_{\mathrm{IN}}(T)$ before plotting due to large uncertainty stemming from poor counting statistics (Hader et al., 2014). The nuclei content of the ultrapure water was measured in the above manner, resulting in $c_{\text {impurties }}(T)$. A best fit line was determined between $-20^{\circ} \mathrm{C}$ and $-35^{\circ} \mathrm{C}$ (approximately a homogeneous freezing point for the size of drops used). No impurities were detected at $T>-20^{\circ} \mathrm{C}$. The effective INP content was determined by subtracting the nuclei content in the water, $c_{\text {impurities }}(T)$, from the measured $c_{\mathrm{IN}}(T)$ in the illite NX suspensions. For most conditions $c_{\text {impurties }}(T)$ was negligible relative to $c_{\mathrm{IN}}(T)$. The ice nucleation surface active site density was then calculated via

$$
n_{\mathrm{s}, \mathrm{BET}}(T)=-\frac{c_{\mathrm{IN}}(T)-c_{\text {impurities }}(T)}{\rho_{\mathrm{w}} w \theta_{\mathrm{N}_{2}}}
$$

where $\rho_{\mathrm{w}}$ is the density of water $\left(997.1 \mathrm{~kg} \mathrm{H}_{2} \mathrm{O} \mathrm{m}{ }^{-3} \mathrm{H}_{2} \mathrm{O}\right), w$ is the mass ratio of dust and water (g dust $\mathrm{g}^{-1}$ water), $\theta_{\mathrm{N} 2}$ is the $\mathrm{N}_{2}$-based SSA obtained by BET analysis $\left(124.4 \mathrm{~m}^{2} \mathrm{~g}^{-1} \mathrm{dust}\right.$ ) and $n_{s, \mathrm{BET}}$ is the BET-normalized IN active surface-site density ( $\left.\mathrm{m}^{-2} \mathrm{dust}\right)$.

Experimental uncertainties: The thermistor embedded in the lower aluminum block was capable of operating in the $-40<T<0{ }^{\circ} \mathrm{C}$ range with a stated tolerance of $\pm 1{ }^{\circ} \mathrm{C}$ (Model TR141-170, Oven Industries). Repeatability of the temperature where 50\% of pure water picodrops froze via homogeneous nucleation was $-35.7 \pm 0.1^{\circ} \mathrm{C}(\mathrm{n}=5$, average diameter of drops $\sim 86 \mu \mathrm{m}$ ). In comparison, Langham and Mason (1958) report a median freezing temperature of drops $\sim-34.4{ }^{\circ} \mathrm{C}$ for this size range. The spread in $n_{s}(T)$ reported as $\square n_{s}(T)=$ 
$\left[n_{s, \text { max }}(T)-n_{s, \min }(T) / n_{s \text {,average }}(T)\right]$ was $\square n_{s}\left(-30^{\circ} \mathrm{C}\right)=0.6(\mathrm{n}=4), \square n_{s}\left(-25^{\circ} \mathrm{C}\right)=1.75(\mathrm{n}=4), \square n_{s}(-$ $\left.23{ }^{\circ} \mathrm{C}\right)=1.28(\mathrm{n}=3)$ and $\square n_{s}\left(-20^{\circ} \mathrm{C}\right)=0.59(\mathrm{n}=2)$.

\section{University of Colorado Raman microscope cold stage (CU-RMCS)}

CU-RMCS has been described previously in detail (Baustian et al., 2010; Schill and Tolbert, 2013). Briefly, a Nicolet Almega XR Raman spectrometer has been coupled to a research grade Olympus BX-51 microscope with 10x, 20x, 50x, and 100x magnification objectives. This Raman microscope has been outfitted with a Linkam THMS600 environmental cell. Temperature of a cold stage inside the cell is controlled by a Linkam TMS94 automated temperature controller with an accuracy of $0.1 \mathrm{~K}$. Water partial pressure inside the cell is controlled by mixing dry and humidified flows of $\mathrm{N}_{2}$ and measured by a Buck Research CR-A1 dew point hygrometer in line with the cell. In the present experiments, however, droplets are isolated from the cell humidity by a layer of silicon oil.

To generate droplets for an immersion freezing experiment, a known wt\% solution of illite NX sample was aspirated into a Meinhard TR-30 glass concentric nebulizer. The concentration of clay in suspensions was determined gravimetrically. Illite NX powder was used as provided without any previous size selection or modification. Clay solutions were mixed for at least 12 hours with a magnetic stir bar prior to use in ice nucleation experiments. To mitigate gravimetric settling prior to nebulization, humidified nitrogen was vigorously bubbled through the clay solutions immediately before aspiration. Humidified $\mathrm{N}_{2}$ was used as the carrier gas to prevent excess evaporation at the nebulizer nozzle. The nebulized spray was directed at a hydrophobically treated fused-silica disc, and the nebulized droplets were allowed to coagulate into supermicron droplets. After nebulization, a drop of silicon oil was placed over the supermicron droplets, and the entire disk was transferred to the environmental cell. Despite low relative humidities inside the cell, droplets inside the drop of silicon oil did not visibly grow or shrink, even after sitting for 12 hours. Prior to each experiment, droplets were examined under 50x magnification to ensure that suspended material was visually evenly distributed between droplets. Thus, the concentration of clay in the droplets was assumed to be the same as the concentration of clay in the bulk solution. Experiments were video recorded under 10x or 20x magnification at 30 frames per second and freezing events were identified by the sudden appearance of structure within droplets. Ice nucleation frozen fractions were calculated as a function of temperature. Depending on the size of the droplets, frozen fraction curves were separated into four different size bins: 10-20 $\mu \mathrm{m}, 20-60 \mu \mathrm{m}, 60$ - 

$120 \mu \mathrm{m}$, and 120-200 $\mu \mathrm{m}$ (lateral diameter). These size bins span droplet volumes from $\sim 0.3$ picoliter to 2.5 nanoliter. In the present experiment, the droplets were cooled from approximately 5 to $-40{ }^{\circ} \mathrm{C}$ at a rate of $10 \mathrm{~K} \mathrm{~min}^{-1}$. Errors in $n_{s}$ values are based on the range of surface areas available in each experiment. The temperature error for all droplets, $0.5 \mathrm{~K}$, were determined by repeated homogeneous freezing experiments on ultra-pure water.

Experimental uncertainties: For CU-RMCS, the errors (\%) in log-scaled $n_{s, \mathrm{BET}}$ $\left(=100 \times \frac{\log \left(n_{s, \mathrm{BET}}^{\text {measred }}\right)-\log \left(n_{s, \mathrm{BET}}^{\text {error }}\right)}{\log \left(n_{s, \mathrm{BET}}^{\text {measred }}\right)}\right)$ derived from surface area deviations were estimated as $4.3 \%$.

\section{FRankfurt Ice Deposition freezinG Experiment (FRIDGE) diffusion cell}

FRIDGE is an isothermal static vacuum vapor diffusion chamber that freezes droplets with immersed particles on a cold stage (S1.1; immersion mode operation) or nucleates ice on dry particles deposited on a substrate (S1.2; default mode operation).

Measurements of immersed particles: Aerosol was generated by dry dispersion of illite NX particles in air and diluted further with purified air. The particle number size distribution of this aerosol in the 0.3-10 $\mu \mathrm{m}$ diameter range was measured by a TSI 3330OPS. Illite NX particles were collected by filtration of the aerosol using cellulose nitrate membrane filters (Millipore, HABP04700). After sampling the filters were placed in vials with $10 \mathrm{~mL}$ of deionized water. Particles were extracted from the filters by agitating for 10 min in an ultrasonic bath. It is noteworthy that the application of the ultrasonic bath and its high efficiency in the washing process for particle removal were demonstrated with a similar experimental setup employed by Ardon-Dryer and Levin (2014). About 80 droplets of $0.5 \mu \mathrm{L}$ volume each were taken from the washing solution with an Eppendorff-pipette and were placed randomly on a silicon wafer on the cold stage. The temperature of the cold stage was lowered by $1{ }^{\circ} \mathrm{C} \mathrm{min}-1$ and the number of drops that froze at each temperature was recorded by the CCD camera and counted. This process was repeated several times with fresh droplets. The actual number concentration of INP derived from this measurement builds on the drop freezing concept of Vali (1971) as modified by Ardon-Dryer and Levin (2014), and is given by 


$$
K^{\prime}(T)=\frac{1}{V} \times\left[\ln \left(N_{0}\right)-\ln (N(T))\right] \times \frac{x}{y}
$$

298

299 where $K^{\prime}(T)$ is the cumulative INP concentration at a temperature $T$. The droplet volume is 300 given by $V, N_{0}$ is the total number of droplets, $N(T)$ is the number of frozen droplets at

301 temperature, $T$. The variable $x$ is the volume of water used to wash the particles from the filter 302 and $y$ the volume of air sampled through the filter.

Experimental uncertainties: FRIDGE measurement uncertainties are $T \pm 0.2{ }^{\circ} \mathrm{C}$ and $304 n_{s} \pm 40 \%$ at $-20{ }^{\circ} \mathrm{C}$. The $n_{s}$ error may become lower with decreasing temperature. Background 305 freezing induced by impurities in the water was observed at $\mathrm{T}<-23{ }^{\circ} \mathrm{C}$. This background 306 freezing contributed to less than $15 \%$ of the overall freezing in the range of $-25{ }^{\circ} \mathrm{C}<\mathrm{T}<-$ $30723{ }^{\circ} \mathrm{C}$ and was accounted for the $n_{s}$ estimation. 
Immersion freezing activity of dry illite NX particles pulverized by a rotating brush generator (PALAS, RBG1000) was investigated using AIDA-CECC. A series of expansion experiments with elevated temperature was performed in the temperature range between -27 and $-35^{\circ} \mathrm{C}$. The results of a total of eighteen expansion experiments with ten polydisperse and eight size-selected illite NX particles (200, 300 and $500 \mathrm{~nm}$ mobility diameter segregated by a DMA) are reported in the present study.

AIDA-CECC consists of an $84 \mathrm{~m}^{3}$ aluminum cylindrical vessel housed in a thermally insulated room. A mechanical pumping system is mounted directly under the AIDA vessel and used for expansion cooling, which actuates cooling during steady pressure drop from 1000 to $800 \mathrm{mb}$ (Möhler et al., 2003). During the expansion cooling experiment controlled by a mechanical pump, the cooling rates of gas temperature in the vessel typically decrease from $\sim 5$ to $<0.1{ }^{\circ} \mathrm{C} \mathrm{min}^{-1}$. The conditions in the vessel, such as temperature and relative humidity, can be continuously homogenized by a mixing ventilator installed on the base of the vessel. The chamber conditions are also monitored by temperature sensors (Möhler et al., 2003) and tunable diode laser (TDL) water vapor absorption measurement (Fahey et al., 2014) prior to and while running each experiment. The use of AIDA for both immersion mode and deposition mode freezing experiment is described in detail in previous reports (e.g., Hiranuma et al., 2014a and 2014b, respectively) so only a brief description is provided here.

For the immersion mode experiment, spontaneous formation of water droplet occurs at water saturation while continuously cooling. Thereafter, water supersaturation condition in the vessel is maintained by controlled mechanical expansion. At droplet activation, most of clay mineral particles are presumably immersed in water drops leading to droplet-freezing at a characteristic temperature (Hiranuma et al., 2014b). Thus, within our definition of singular freezing, immersion ice nucleation activity of clay minerals solely depends on temperature.

Temporal evolution of size distribution and associated particle phase is measured using the welas optical spectrometers (PALAS, Sensor series 2300 and 2500; Benz et al., 2005) and a light scattering instrument, Streulicht-intensitätsmessungen zum optischen 
mounted to the wall of the AIDA vessel. Two independent sensors of a welas deployed on the bottom vessel of AIDA in side by side position are used together to measure ice crystal size distributions over the size range of 0.5 to $150 \mu \mathrm{m}$ optical diameter every $5 \mathrm{~s}$. Assuming spherical shape of particles, the optical diameter is equivalent to a volume equivalent geometric diameter. The droplet-ice threshold diameter, $D_{\text {thresh }}$, is determined by SIMONE depolarization measurements (Schnaiter et al., 2012). The total ice number was calculated by summing ice numbers above the observed $D_{\text {thresh }}$, typically $\sim 30 \mu \mathrm{m}$ diameter. For the immersion experiments, we typically observe a full activation of droplets (i.e. number of droplets, $N_{\text {droplet }}>$ number of aerosols, $N_{\mathrm{ae}}$ ), but in case of incomplete droplet activation (i.e. $N_{\text {droplet }}<N_{\text {ae }}$ ), the total geometric surface is normalized to a droplet number measured by a welas-OPC.

Experimental uncertainties: Temperature and humidity uncertainty is $\pm 0.3{ }^{\circ} \mathrm{C}$ and \pm 5\%, respectively (Möhler et al., 2003; Fahey et al. ,2014). The uncertainty involved in the $n_{s}$ estimation for immersion freezing in AIDA-CECC was previously estimated as $35 \%$ (Steinke et al., 2011).

\section{CSU Continuous Flow Diffusion Chamber (CSU-CFDC)}

CSU-CFDC operating principles are described in the earlier works of Rogers (1988), Rogers et al. (2001) and Eidhammer et al. (2010). The current versions of CSU-CFDC used in ground based (CFDC-1F) and aircraft studies (CFDC-1H) are geometrically identical and composed of cylindrical walls that are coated with ice via flooding and expelling water from the chamber when the walls are set at a controlled temperature of $\sim-27^{\circ} \mathrm{C}$ before each experimental period. The plate separation is $1.12 \mathrm{~cm}$ prior to ice application, which has a typical thickness of $0.015 \mathrm{~cm}$. The chamber is divided into two sections vertically, separated by a Delrin collar. A temperature gradient between the colder (inner) and warmer (outer) ice walls in the upper $50 \mathrm{~cm}$ section creates an ice supersaturated field into which an aerosol lamina is directed. The Delrin inlet manifold has a stainless steel knife edge ring threaded into it, so that aerosol flow is directed centrally between two sheath flows of clean and dry air. The ratio of aerosol and sheath flows can be varied, but typically the aerosol lamina represents $15 \%$ of the $10 \mathrm{~L} \mathrm{~min}^{-1}$ total flow. Ice crystals forming on ice nuclei in the growth region of the chamber enter the lower $30 \mathrm{~cm}$ "evaporation" section of the chamber where the two walls are held equivalently to the original low (inner) wall temperature. When the temperature gradient 
in the growth section is adjusted to create water supersaturated conditions that activate cloud droplets, these will evaporate to haze sizes in the evaporation section, at least up to some $\mathrm{RH}_{\mathrm{w}}$ where they survive, referred to by many as the droplet breakthrough $\mathrm{RH}_{\mathrm{w}}$. Until that high $\mathrm{RH}_{\mathrm{w}}$, only ice crystals and haze particles will exit the CFDC. Upstream of the CFDC, aerosol particle concentrations are measured by a CPC, sometimes after size selection with a DMA. Small numbers of large aerosol particles are removed just in advance of the CFDC inlet manifold using dual single-jet impactors typically set to cutpoint sizes between 1.5 and 2.4 $\mu \mathrm{m}$ depending on the nature of the experiment. Ice crystals and aerosols exiting the CFDC at sizes above approximately $500 \mathrm{~nm}$ are counted with an OPC, where the two populations are readily distinguished in different size modes. For the data collected in this work, we counted all particles in size bins above $3 \mu \mathrm{m}$ as ice particles.

Present CFDC-1F measurements were focused into 5-10 min periods of sampling alternating with periods in which the aerosol sample was filtered in order to determine background frost influences on ice particle counts in the OPC, as described in a number of prior publications. Background counts were quite low, and so were subtracted as a simple average of filter periods before and after sampling.

Polydisperse illite NX particles were generated for size selection using the simple flask generator as described in Tobo et al. (2014). For collection of size-selected particles, several grams of dust were placed in a $250 \mathrm{~mL}$ conical flask, and dust released by blowing nitrogen in at the base $\left(\sim 2 \mathrm{~L} \mathrm{~min}^{-1}\right)$ while agitating the flask in an ultrasonic bath. The particle stream was passed through a dilution tank $\left(\mathrm{N}_{2}\right.$ flow rate into the tank $\left.\sim 5 \mathrm{~L} \mathrm{~min}^{-1}\right)$ and then through ${ }^{210} \mathrm{Po}$ neutralizer before size selection of particles with a mobility diameter of $500 \mathrm{~nm}$ in a DMA (TSI Inc., Model 3081; sheath flow: $4.5 \mathrm{~L} \mathrm{~min}^{-1}$, sample flow: $1.8 \mathrm{~L} \mathrm{~min}^{-1}$ ). This stream was then divided, with $0.3 \mathrm{~L} \mathrm{~min}^{-1}$ passed to a CPC (TSI Inc., Model 3010) and 1.50 $\mathrm{L} \mathrm{min}^{-1}$ drawn by the CFDC. The activated fraction was calculated by taking the ratio of the ice crystal number concentration to the total particle number concentration measured with the CPC.

For comparison with other IN instruments measuring in the immersion mode, we follow Sullivan et al. (2010a and 2010b) and a number of other papers from the CSU group in processing aerosol at $\mathrm{RH}_{\mathrm{w}} \approx 105 \%$, with the understanding that higher active fractions of mineral dusts have been noted in processing up to about $110 \% \mathrm{RH}_{\mathrm{w}}$ (Petters et al., 2009; DeMott et al., 2011). We did not raise $\mathrm{RH}_{\mathrm{w}}$ to these higher levels in these studies so that we could avoid any influence of droplet breakthrough. We do now report that for representative atmospheric mineral dusts, activation at $105 \% \mathrm{RH}_{\mathrm{w}}$ likely underestimates the active fraction 
measured at $109 \% \mathrm{RH}_{\mathrm{w}}$ by the CFDC by a factor of 3 across a broad temperature range (DeMott et al. 2014).

Particle losses in upstream tubing, the aerosol impactor, and the inlet manifold of the CFDC have been previously estimated as $30 \%$ of total condensation nuclei when sampling ambient air (Rogers et al. 2001), but only $10 \%$ for aerosols in the 100 to $800 \mathrm{~nm}$ size range based on laboratory tests (Prenni et al. 2009). We did not correct for such losses in the ice nuclei data for $500 \mathrm{~nm}$ particles reported for the CFDC.

Experimental uncertainties: The thermodynamic conditions in the CFDC are inferred based on measurements of chamber pressure, wall temperatures and flow rates. Results are reported for the calculated average aerosol lamina position. The solution for the lamina position, and thus its temperature and supersaturation, requires numerical solution (Rogers, 1988), thus making the calculation of uncertainty in the conditions more complex than propagation of error. Richardson (2009) used Monte-Carlo methods to estimate the uncertainty in reported lamina temperature and supersaturation, assuming the typical $1{ }^{\circ} \mathrm{C}$ temperature variation along the length of the CFDC cylindrical walls. On this basis, temperature uncertainty is $\pm 0.5^{\circ} \mathrm{C}$ at the reported CFDC processing temperature, independent of processing temperature. Supersaturation uncertainty was found by Richardson (2009) to depend inversely on temperature. This uncertainty may be approximated by the relation $\square \mathrm{RH}_{\mathrm{w}}(\%)=21.8-0.08 T$ (in Kelvin). Thus, $\square \mathrm{RH}_{\mathrm{w}}$ uncertainty is $\pm 1.6,2$ and $2.4 \%$ at $-20,-25$, and $-30{ }^{\circ} \mathrm{C}$, respectively. This temperature uncertainty propagates into and $n_{s}$ uncertainty of $\pm 60 \%$ at any temperature. This dominates over the variation in $N_{\text {ice }}$ at any temperature when $N_{\text {ice }}$ is determined for statistically meaningful sample periods, as reported.

\section{ElectroDynamic Balance (EDB) levitator}

The EDB setup was used for investigation of the contact and immersion freezing of levitated supercooled water droplets colliding with the illite particles. The setup used for the contact freezing experiments is described in detail by (Hoffmann et al., 2013a and 2013b) and therefore only briefly explained here. The centerpiece of the setup is an electrodynamic balance (EDB) for levitating charged water microdroplets. The droplets with diameter of 90 $\mu \mathrm{m}$ are produced by a piezoelectric injector (GeSIM model A010-006 SPIP, cylindrical housing) and charged via induction to the value of $1 \mathrm{pC}$ (Rzesanke et al., 2012). The aerosol is generated by a fluidized bed generator operated with synthetic air followed by a multistage impactor to eliminate the super micron particles from the aerosol flow. Specifically, the multi- 
orifice rotating stage cascade impactor (LPI-ROT 25/0018, HAUKE) operated with five impactor stages (largest cut-off diameter $2 \mu \mathrm{m}$ ) was used as described in Hoffmann et al. (2013b). Only particles of the desired electrical mobility diameter (750, 550 and $320 \mathrm{~nm}$, as preselected by Differential Mobility Analyzer, TSI Inc., Model 3081) were allowed to enter EDB. After EDB, the particle number concentration was counted by an Ultrafine Condensation Particle Counter (UCPC, TSI Inc., Model 3776).

To perform immersion freezing experiments we have modified the setup in the following way. The supercooled water droplet was exposed to the flow of the aerosol particles only for a limited time $t_{1}$. During this time the droplet, if not frozen via contact nucleation mechanism, has collected average number of particles equal to the product of collision rate (calculated theoretically) and the time $t_{1}$. After that, the aerosol particles were removed from the flow by switching on the electrostatic precipitator installed just in front of EDB. For $t>t_{1}$ the droplet can only freeze via the immersion freezing pathway induced by the particles it has already collected during $t<t_{1}$.

To compare contact and immersion freezing results we calculate the ice nucleation active surface-site density, $n_{s}$, which is given by the following equations:

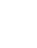

85

9

$$
\begin{aligned}
& t<t_{1}\left(\text { contact mode): } n_{\mathrm{S}}(T)=-\frac{\ln \left(1-f_{\mathrm{ice}}(T)\right)}{S_{\mathrm{IN}} n_{\mathrm{c}} t}=\frac{e_{\mathrm{c}}}{S_{\mathrm{IN}}}\right. \\
& t>t_{1}\left(\text { immersion mode) }: n_{\mathrm{S}}(T)=-\frac{\ln \left(1-f_{\mathrm{ice}}^{*}(T)\right)}{S_{\mathrm{IN}} n_{\mathrm{c}} t_{1} t}\right.
\end{aligned}
$$

where $f_{\text {ice }}$ is the frozen fraction after time $\mathrm{t}, e_{\mathrm{c}}$ is the probability of freezing on a single contact, $n_{\mathrm{c}}$ is a collision rate, $S_{\mathrm{IN}}$ is surface area of a single ice-nucleating particle, $f_{\mathrm{ice}}^{*}$ is a fraction of droplets frozen heterogeneously after the aerosol flow was switched off.

\section{Experimental uncertainties: The temperature uncertainty is $T \pm 0.2{ }^{\circ} \mathrm{C}$, and the} uncertainty of the freezing probability is $e_{c} \pm 35 \%$. The uncertainty for $n_{s}$ depends on the uncertainty of the BET surface. Assuming a BET uncertainty of $10-20 \%$, the uncertainty is $n_{s}$ $\pm 50-69 \%$. 


\section{Fast Ice Nucleus CHamber (FINCH)}

470

471

472

473

474

475

476

477

478

479

480

481

482

483

484

485

486

487

488

489

490

491

492

493

494

495

496

497

498

FINCH is an online instrument in which aerosol particles are activated to ice crystals under different freezing temperatures and supersaturations. It consists of a chamber (stainless steel tube, $80 \mathrm{~cm}$ in length, $8.6 \mathrm{~cm}$ inner diameter) for which the wall can be cooled down to temperatures between 0 and $-65^{\circ} \mathrm{C}$. Inside the chamber a specific supersaturation and temperature is reached by mixing the sample flow of ambient aerosol with a warm moist and a cold dry airflow (Bundke et al., 2008). By changing the flow rates and/or temperatures of the individual airflows the chamber supersaturation and freezing temperature can be varied relatively quickly. Ice-nucleating particles entering the chamber are activated and grow to sizes of a few micrometers. At the end of the growth tube they are counted in an optical particle counter (OPC) similar to the detector described in Bundke et al. (2010) (405 nm wavelength laser with a power of $100 \mathrm{~mW}$ ). It is able to distinguish between water droplets and ice crystals by analyzing the polarization ratio of the scattered circular polarized light (P44/P11 ratio of the scattering matrix; Hu et al., 2003) and detects the auto-fluorescence following from excitation of the grown particles with UV light, which is an indication for biological particle material.

The presented FINCH illite NX dataset was obtained during a joint campaign with LACIS at the Leibniz Institute for Tropospheric Research (TROPOS) facility. Therefore the aerosol generation is identical as described for the LACIS experiments (see below). Sizeselected illite NX particles of $500 \mathrm{~nm}$ in diameter were fed into $\mathrm{FINCH}$, which was operated at a saturation ratio above water saturation and at temperatures between -21 and $-28{ }^{\circ} \mathrm{C}$. The frozen fraction, $\alpha$, was calculated by division of the $N_{\text {ice }}$ detected by FINCH at a certain freezing temperature and the number concentration of all particles, which was measured in parallel to FINCH by a CPC (TSI Inc., Model 3010).

Experimental uncertainties: The FINCH uncertainties for the freezing temperature are in the range of $\pm 1.5^{\circ} \mathrm{C}$ and $\pm 30 \%$ for $n_{s}$. A potential systematic over-estimation of the freezing temperature due to imperfect mixing of the individual airflows are a matter of current investigations. 


\section{FRankfurt Ice Deposition freezinG Experiment (FRIDGE) diffusion cell}

FRIDGE is an isothermal static vacuum vapor diffusion chamber that freezes droplets with immersed particles on a cold stage (S1.1; immersion mode operation) or nucleates ice on dry particles deposited on a substrate (S1.2; default mode operation).

Dry particle measurements: The default mode operation of FRIDGE provided data at -18 and $-25{ }^{\circ} \mathrm{C}$ (a total of ten data points with five points at each temperature). INPs were collected from the dry illite NX particles in AIDA by electrostatic precipitation of the particles onto silicon wafers of $45 \mathrm{~mm}$ diameter. After sampling the wafers were placed on the cold table in the FRIDGE isothermal chamber ( $500 \mathrm{~mL}$ volume; Klein et al., 2010$)$, which was then evacuated. Upon inflation of water vapor into the chamber ice crystals grew on the INP, were photographed by a CCD camera, and were counted automatically for around $100 \mathrm{~s}$. It is assumed that one ice crystal represents one INP active at the selected temperature and vapor pressure. Crystals can be evaporated by evacuation of the chamber, and the measurement can be repeated at another temperature and/or supersaturation. The cold stage temperature can be regulated from 0 to $-35^{\circ} \mathrm{C}$.

Experimental uncertainties: FRIDGE measurement uncertainties are $T \pm 0.2{ }^{\circ} \mathrm{C}$ and $n_{s} \pm 40 \%$ at $-20{ }^{\circ} \mathrm{C}$. The $n_{s}$ error may become lower with decreasing temperature.

\section{Leipzig Aerosol Cloud Interaction Simulator (LACIS)}

LACIS was used in its immersion freezing mode (Hartmann et al., 2011) to study immersion freezing efficiency of illite NX particles. LACIS measurements were performed on size segregated particles. Particle generation was done using a similar setup as e.g. described in Wex et al. (2014). In short, illite NX particles were made airborne using a fluidized bed. Subsequently, particles larger than those which should be examined were removed from the aerosol using a micro orifice uniform deposition impactor (MOUDI, MSP Corporation, USA, Model 100R) and a cyclone. Downstream, a neutralizer established a bipolar equilibrium charge distribution on the particles. Then particles were size-selected by a DMA (Type Vienna Hauke medium; aerosol to sheath air flow ratio of 1:10), and selected particle sizes were 300,500 and $700 \mathrm{~nm}$. The aerosol was then provided for further analysis. 
The before mentioned removal of larger particles was done to minimize the number of multiply charged particles that pass the DMA, and measurements with a UHSAS (Ultra-High Sensitivity Aerosol Spectrometer, DMT) behind the DMA were done to confirm that the number of multiply charged particles could be neglected.

Size-selected aerosol particles were also fed into a CPC (TSI Inc., Model 3010), and into LACIS. LACIS is a flow tube, consisting of 7 sections where each is $1 \mathrm{~m}$ long. Each section can be temperature controlled separately. Temperatures can go down to $-40{ }^{\circ} \mathrm{C}$. Before entering the flow tube, by use of a humidifier (Perma Pure, PH-30T-24KS), the sheath air stream is hydrated such that droplets form on the aerosol particles upon cooling, i.e. while passing through the flow tube. The droplets can subsequently freeze, depending on the nature of the immersed aerosol particle and the adjusted temperature. At the LACIS outlet, a homebuilt optical particle spectrometer (Clauss et al., 2013) is used to determine if the arriving hydrometeors are liquid droples or frozen ice crystals. This information then is used to derive a frozen fraction, $\alpha$.

Experimental uncertainties: The temperature uncertainty is $T \pm 0.3 \mathrm{~K}$, the uncertainty of the measured $\alpha$ is on average $\pm 27.4 \%$. The uncertainty in $n_{s}$ was calculated accounting for this measurement uncertainty and for the uncertainty related to the width of the transfer function in the DMA, which was assumed to be $5 \%$. The resulting uncertainty in $n_{s}$ derived from LACIS data is $28 \%$.

\section{Meteorological Research Institute Dynamic Controlled Expansion Cloud-simulation} Chamber (MRI-DCECC)

The DCECC at Meteorological Research Institute (MRI) in Tsukuba, Japan (Tajiri et $a l ., 2013)$ was used to investigate immersion freezing properties of dry illite NX particles. The DCECC can simulate quasi-adiabatic expansions by synchronously controlling air pressure and inner wall temperature of the chamber vessel. MRI-DCECC warrants experiments with atmospherically relevant droplet sizes as well as controllable droplet onset temperature ( $\left.T_{\text {droplet,onset }}\right)$ and supersaturation conditions resulting in freezing of particles in water droplets. Dry illite NX particles were aerosolized by a rotating brush generator (PALAS, RBG1000) and injected into the ventilated $1.4 \mathrm{~m}^{3}$ chamber vessel. All experiments were performed by employing a constant cooling rate of about $-3{ }^{\circ} \mathrm{C} \mathrm{min}^{-1}$ (equivalent to the updraft rate of about $5.0 \mathrm{~m} \mathrm{~s}^{-1}$ ) from initial gas temperature typically about $5{ }^{\circ} \mathrm{C}$. The DCECC is equipped with 
various devices, such as an SMPS, a welas-OPC, an APS and a CPC, for sensing cloud formation and measuring size distributions and shapes of aerosol and cloud particles from 0.01 to several hundred micrometers in size. As these instruments were also employed at AIDA-CECC, the procedures to calculate the total ice number and total geometric surface were also consistent with AIDA measurements.

Experimental uncertainties: The temperature uncertainty in MRI-DCECC is $T \pm 1.0$ ${ }^{\circ} \mathrm{C}$ for the evacuation rate corresponding to $5.0 \mathrm{~m} \mathrm{~s}^{-1}$. The $40 \%$ uncertainty for $n_{s}$ was derived from the errors in the measurements of $N_{\text {ice }}$ by a welas (20\%; Möhler et al., 2006) and surface area estimation (34\%). More specifically, the uncertainty for surface area estimation was derived from the relative standard deviation of the $10 \mathrm{~s}$ time-averaged welas surface measurements for approximately 5 min prior to expansion experiments (i.e., MRI02_131001a, MRI02_131003b and MRI02_131004).

\section{Portable Ice Nucleation Chamber (PINC)}

PINC operation principle is based on the Continuous Flow Diffusion Chamber (Rogers, 1988). Two flat parallel plates $(568 \times 300 \mathrm{~mm})$ whose inner walls coated with ice before each experiment are temperature controlled so as to apply a temperature gradient between the ice layers leading to a supersaturation with respect to ice and water. This allows ice crystals to form and grow on ice nuclei in the water sub-saturated $\left(\mathrm{RH}_{\mathrm{w}}<100 \%\right)$ and supersaturated $\left(\mathrm{RH}_{\mathrm{w}}>100 \%\right)$ regimes thus inferring deposition and condensation freezing respectively. Any water drops that may form will evaporate in the evaporation section downstream of the freezing chamber. Upstream of PINC, aerosol particles are counted with a $\mathrm{CPC}$ after flowing through an impactor with a $D_{50}$ cutoff at $0.91 \mu \mathrm{m}$ aerodynamic diameter (Chou et al., 2011). The ice crystals are counted with an OPC at the exit of PINC and are distinguished from the small, unactivated aerosol particles by their size. For the data collected in this work, we counted all particles in size bins above $2 \mu \mathrm{m}$ to be ice particles since the illite NX particles we sampled were 500 and $1000 \mathrm{~nm}$ in diameter. Measurements conducted for 3 min before each sample and one minute after a sample were averaged in order to determine the background signal in the OPC. These values were then subtracted from the IN concentrations obtained during sample measurement to correct for the background. Further details on the PINC design and operation are described in Chou et al. (2011) and Kanji et al. (2013). 
Polydisperse illite NX particles that were suspended in the $4 \mathrm{~m}^{3}$ volume aerosol buffer chamber were size-selected using a DMA and counted using a CPC after which they were sampled by PINC. The activated fraction is calculated by taking the ratio of the ice crystal number concentration to the total particle number concentration measured with the CPC. Particles with diameters 500 and $1000 \mathrm{~nm}$ were size-selected using the Maxi-DMA developed at the TROPOS and described in more detail elsewhere (Raddatz et al., 2013).

For comparison with other IN counters measuring in immersion mode, only IN data taken by PINC at $\mathrm{RH}_{\mathrm{w}} \geq 104 \%$ and below the $\mathrm{RH}_{\mathrm{w}}$ at which droplets survive past the evaporation section $\left(\mathrm{RH}_{\mathrm{w}, \mathrm{ds}}\right)$, are presented. For each temperature, $\mathrm{RH}$ was scanned continuously from $\mathrm{RH}_{\mathrm{ice}}=100 \%$ up to $\mathrm{RH}_{\mathrm{w}, \mathrm{ds}}$. $\mathrm{RH}_{\mathrm{w}, \mathrm{ds}}$ lies for $T=-20{ }^{\circ} \mathrm{C}$ at $105 \%$ and at -38 ${ }^{\circ} \mathrm{C}$ at $109 \%$.

Particle losses in the tubing and the impactor upstream of PINC were accounted for by a particle loss curve determined for kaolinite particles with a mobility diameter between $500-$ $950 \mathrm{~nm}$. As such the data for 500 and $1000 \mathrm{~nm}$ particles have been corrected for losses through the impactor of 25 and $60 \%$ respectively.

At lower temperatures, the results show reasonable agreement with AIDA and LACIS measurements, however at higher temperatures $\left(-25^{\circ} \mathrm{C}\right)$ we find that for the $1000 \mathrm{~nm}$ particle we underestimate the $n_{s}$ compared to LACIS for example. The reason for this is that we do not have enough residence time in the growth and nucleation section of PINC (residence time of 4-5 s) to fully activate the particles into droplets and as such underestimate the activated fraction in immersion mode. The way to compensate for this would be to sample at higher $\mathrm{RH}_{\mathrm{w}}$ (as we do for lower temperatures), but at higher temperatures we are limited by the water drop survival line $\left(\mathrm{RH}_{\mathrm{w}}=105 \%\right)$ so we cannot compensate for the short residence time by taking data points at higher $\mathrm{RH}_{\mathrm{w}}$. As such, data taken for immersion freezing at higher temperatures could mean that we are underestimating immersion freezing, or rather be reporting deposition nucleation or condensation freezing.

Experimental uncertainties: Temperature uncertainties are on the order of $\pm 0.1{ }^{\circ} \mathrm{C}$ resulting in a relative uncertainty of $\pm 2 \%$ in $\mathrm{RH}$. The temperature uncertainty results in a variation across the sample lamina of $\pm 0.4{ }^{\circ} \mathrm{C}$. Uncertainty in $N_{\text {ice }}$ (From OPC) is $10 \%$ and surface area estimate is about $25 \%$ resulting in an uncertainty in $n_{s}$ of $\pm 27 \%$. 
Heterogeneous ice nucleation properties of illite NX dust particles generated by the small-scale powder disc-disperser (SSPD, TSI, Model 3433) were investigated using ice nucleation chamber located at Atmospheric Measurement Laboratory, an atmospheric sciences laboratory at Pacific Northwest National Laboratory (PNNL), WA., USA. The working principle of PNNL compact ice chamber (PNNL-CIC) has been described in the literature (Stetzer et al., 2008; Friedman et al., 2011; Kulkarni et al., 2012); its design and experimental details are as follows. PNNL-CIC is a continuous flow diffusion chamber consisting of two flat, vertical parallel aluminum plates that are cooled and covered with a layer of ice. The chamber also has an evaporation section attached at the bottom of the chamber to remove water droplets. The chamber design ensures that aerosols are exposed to constant temperature and $\mathrm{RH}_{\text {ice }}$ over the length of the chamber. Saturation vapor pressures over ice and water are calculated using formulations published by Murphy and Koop (2005). The chamber wall temperatures are controlled by using two external cooling baths (Lauda Brinkmann Inc.), and temperature data are logged using the National Instrument CompactRIO programmable automation controller (cRIO-9114 combined with cRIO-9022). The chamber plates are temperature controlled independently to develop a linear temperature gradient across them, which according to the principle of thermal gradient diffusion theory, produces a supersaturation profile between the plates (e.g., Rogers et al., 1988). Recently we modified the evaporation section design, such that this section now has separate cooling bath and its temperature is independently controlled. Temperature of the evaporation section is typically maintained at $\sim-32{ }^{\circ} \mathrm{C}$. At the beginning of the experiment, the chamber walls are coated with an $\sim 0.5 \mathrm{~mm}$ thick ice layer, and the temperature gradient is set at zero, which creates icesaturation conditions inside the chamber $\left(\mathrm{RH}_{\mathrm{ice}}=100 \%\right)$, Then, the refrigeration system cools one plate and warms the other to increase the $\mathrm{RH}_{\text {ice. }}$ The total flow used is $11 \mathrm{~L} \mathrm{~min}^{-1}$; sheath and sample flows used were 10 and $1 \mathrm{~L} \mathrm{~min}^{-1}$, respectively, which limits the aerosol residence time to $\sim 12 \mathrm{~s}$ within the CIC. Ice nucleates on the aerosol particles and the newly formed ice crystal grows to a size greater than the original aerosol size, and ice crystals $>3 \mu \mathrm{m}$ exiting the chamber are counted with an OPC (CLiMET, model CI-3100). The ice active fraction was calculated as the ratio of number of ice crystals measured by the OPC to the condensation nuclei available for nucleation. Background ice nuclei concentrations were calculated to estimate the lower detection limit of an $\alpha$. The lower detection limit of $\alpha$ was $<0.01 \%$. To 
make sure our background IN concentrations are less than $0.01 \%$, we restrict our experimental time to less than 3 hours.

Experimental uncertainties: Temperature uncertainty is $\sim \pm 0.3{ }^{\circ} \mathrm{C}$. For $n_{s}$ the uncertainty arises from $N_{\text {ice }}$ measurement and surface area estimation. The resulting error is \pm one order of magnitude at any $n_{s}(T)$ space.

\section{Zurich Ice Nucleation Chamber with Immersion Mode Cooling chAmber (IMCA-ZINC)}

ZINC is a parallel plate CFDC type chamber developed by Stetzer et al. (2008) following the design described in the work of Rogers (1988). The chamber inner-walls are coated with ice prior to experiments. Under equilibrium conditions, linear temperature and vapor pressure gradients are established between the warmer and colder walls creating supersaturated conditions with respect to ice or water in the chamber volume. The two chamber walls are separately temperature-controlled by two cryostats (Lauda RP890). Independent temperature control of the two walls enables experiments at relative humidity conditions ranging from ice saturation until several hundred per cent of water saturation. An evaporation section, where both walls are kept at the same temperature to create ice saturated but water-sub-saturated conditions, is able to evaporate potentially formed droplets, before being sampled by an OPC. Deposition mode experiments are conducted by scanning through relative humidity space while keeping the experimental temperature constant by increasing the temperature gradient between the two wall plates. The streamline of the injected illite NX particles (generated by a combination of a TSI fluidized bed, a series of URG cyclone impactors and a TSI DMA; Welti et al., 2009) is maintained at approximately the center position between the ice coated walls by two layers of particle-free sheath air. At the exit of ZINC, ice crystals are detected and distinguished from inactivated particles by size using an OPC (Climet Cl-3100). The particle concentration introduced into the experiment is detected with a butanol-CPC (TSI 3010).

The IMCA chamber was developed by Lüönd et al. (2010) as a vertical extension to ZINC and has the same parallel plate geometry. The walls are layered with continuously wetted filter papers and temperature controlled. Similar to ZINC, a horizontal temperature gradient is applied to create supersaturation with respect to water between the walls. When entering IMCA, particles are exposed to $120 \%$ saturation with respect to water at $40{ }^{\circ} \mathrm{C}$ to 
692 trigger droplet formation and growth. Subsequently, a vertical temperature gradient is 693 established to cool the formed droplets down to the experimental temperatures prevailing in 694 ZINC. For immersion freezing experiments ZINC is held at water saturated conditions to 695 prevent evaporation or droplet growth. Droplets and ice crystals are detected in line before 696 entering ZINC's evaporation section using the Ice Optical DEpolarization detector (IODE) 697 described in Nicolet et al. (2010). IMCA-ZINC combination mimics an atmospheric pathway 698 where particles are activated as cloud droplets at temperatures above $0{ }^{\circ} \mathrm{C}$, subsequently 699 cooled and exposed to sub-zero temperatures at which freezing can occur. Experimental uncertainties: Temperature uncertainty is $\pm 0.4{ }^{\circ} \mathrm{C}$. The uncertainties 701 in $n_{s}(T)$ are propagated from the uncertainties in IODE and the surface area $( \pm 25 \%)$. 


\section{S2. Supplementary Figures}

703

704

705

706

707

708

709

710

711

712

An X-ray diffraction measurement was performed by a Panalytical X`Pert Pro device (fixed divergence, $40 \mathrm{kV}, 30 \mathrm{~mA}, \mathrm{CuK}_{\mathrm{a}}$ exication). For data analysis the X'Pert Pro software was applied. While we successfully identified several different forms of orthoclase (KAlSi3O8) with some Na inclusion, we cannot specify the type of K-feldspar polymorphs (e.g., microcline). Therefore, we define the feldspar as orthoclase or sanidine in the present study.

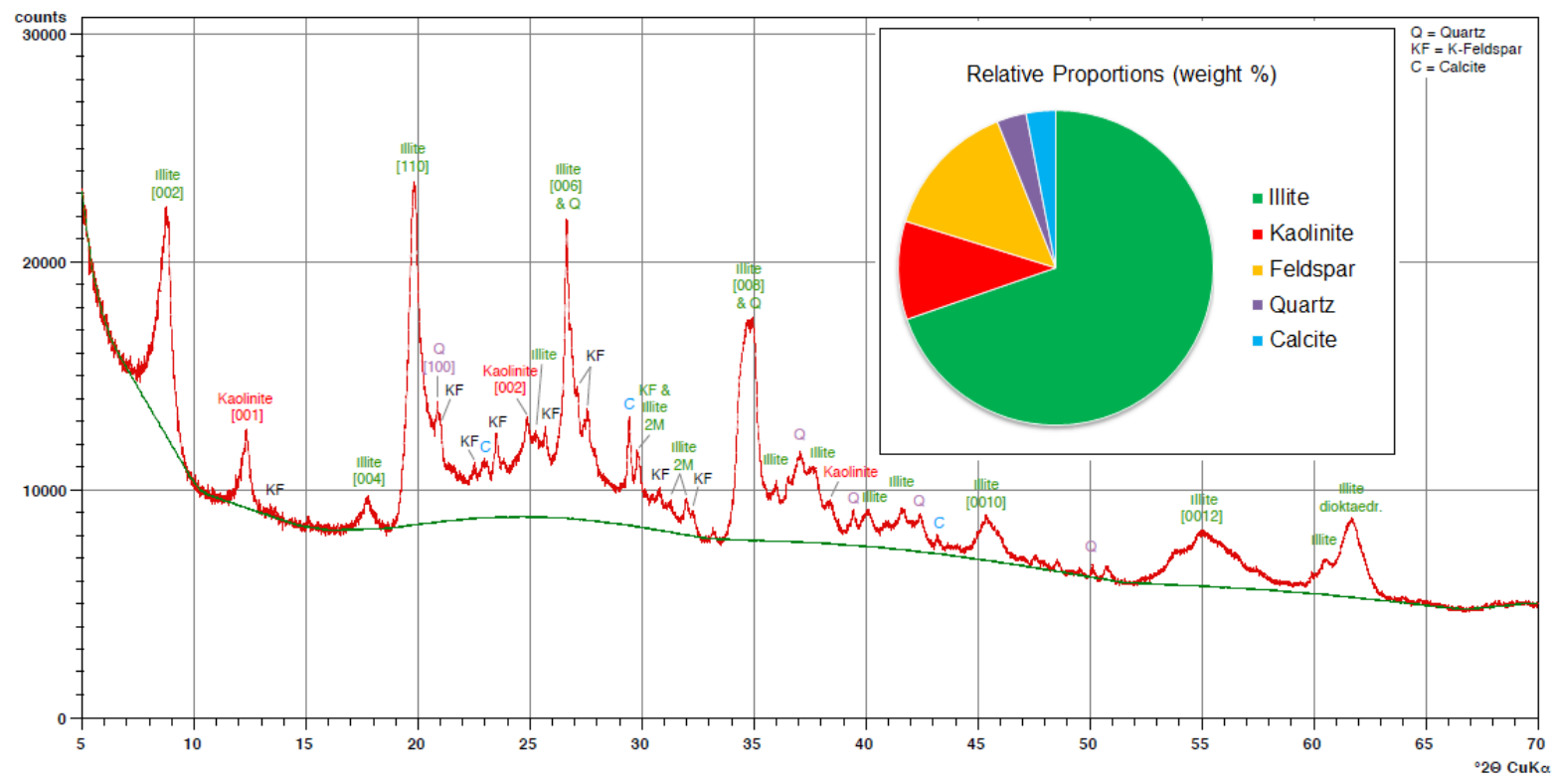

Figure S1. X-ray diffraction spectrum of the illite NX sample. The pie chart reflects the wt\% presented in Table 2 (this study). 


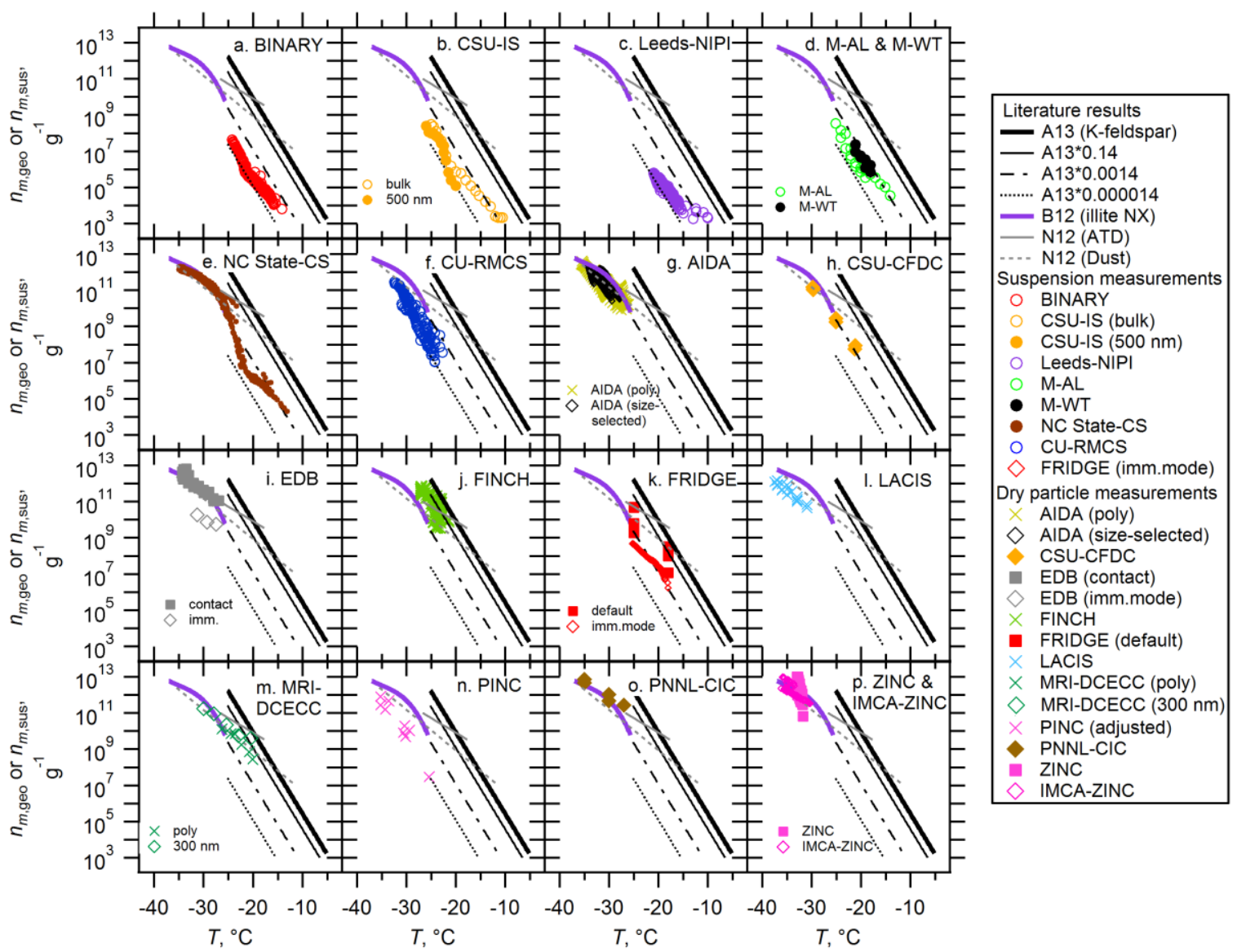

Figure S2. Inter-comparison of seventeen instruments with $n_{m, \text { geo }}$ or $n_{m, \text { sus }}$ (for dry-dispersed particle and suspension measurements, respectively). Note that M-AL and M-WT results are presented in single panel (d). In (k), FRIDGE results of default (solid square) and imm.mode (open diamond) are presented. Both ZINC (solid square) and IMCA-ZINC (open diamond) data are shown in (p). Reference immersion freezing $n_{s}(T)$ spectra for illite NX (B12), K-feldspar (A13), ATD and desert dusts (Dust) (N12) are also shown (See Sect. 3.2). 
The linear space $n_{s}$ average as presented in Fig. 8 may bias the fit to higher $n_{s}$ values.

725 Therefore, we present $T$-binned $n_{s, \mathrm{BET}}(T)$ and $n_{s, \text { geo }}(T)$ spectra averaged in the 'log space' in

726 Fig. S3a and b, respectively. In a similar way to the presentation in Fig. 8, panels i, ii and iii of

727 Fig. S3 show $T$-binned data averaged in the log space of all seventeen instruments, all suspension type measurements, and all measurements that involved dry particles, respectively, while panel iv shows a comparison between suspension and dry-particle measurements. To be comparable with Fig. 8, the data from 'EDB (contact)' and 'ZINC' (Welti et al., 2009) were not used to generate T-binned data. As can be seen in both Fig. S3 and Fig. 8, there seems a different trend between suspension and dry-dispersed particle measurements for this mineral dust. Thus, the choice of averaging procedure does not influence our data interpretation of the observed deviation (i.e., $n_{s}$ from dry-dispersed methods $>n_{s}$ from suspension methods) in this study.
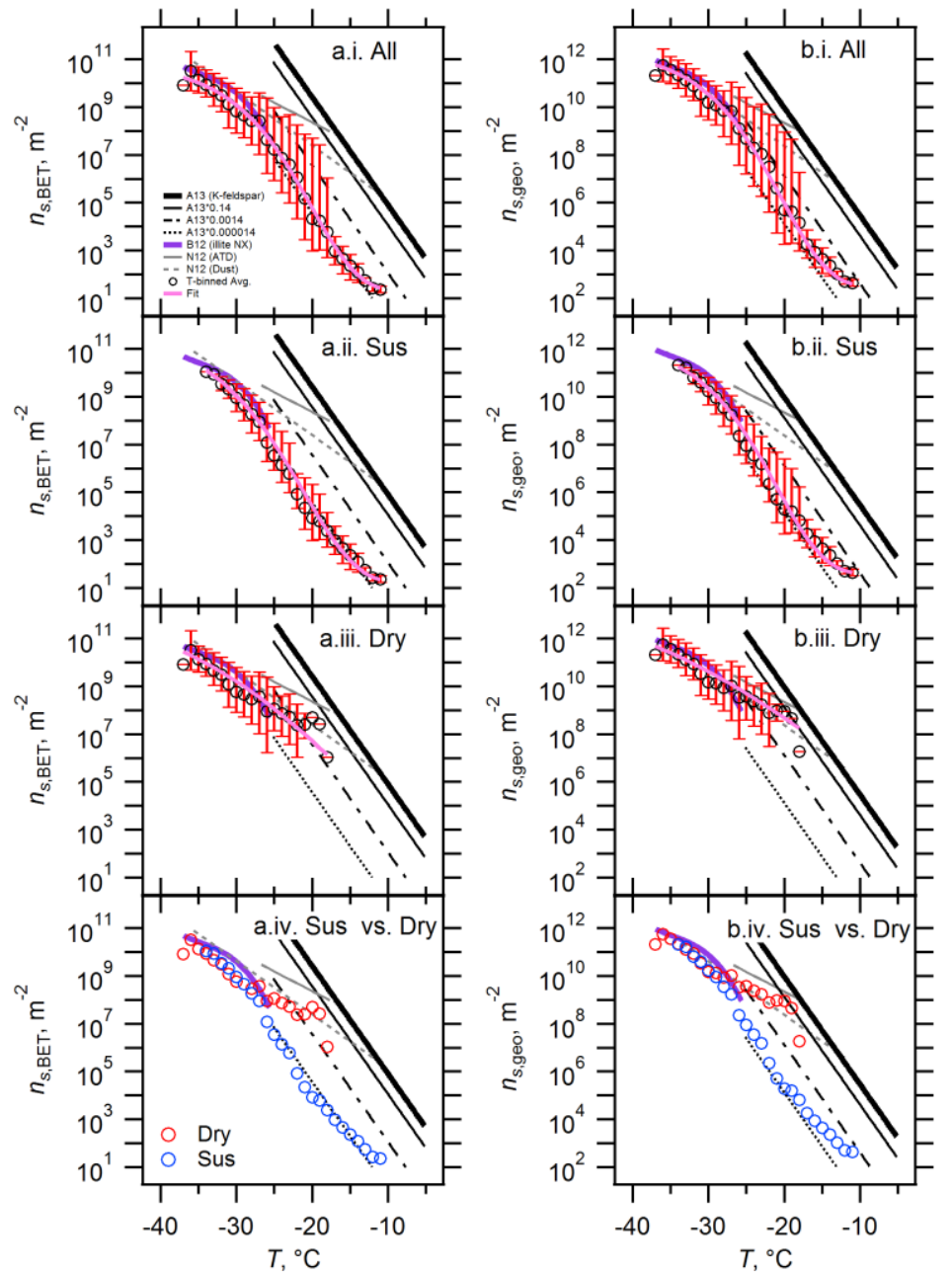

Figure S3. $T$-binned spectra based on $n_{s, \text { geo }}$ (a) and $n_{s, \mathrm{BET}}$ (b). $T$-binned data (i.e., average in the log space with 1 ${ }^{\circ} \mathrm{C}$ bins for $-37{ }^{\circ} \mathrm{C}<T<-11{ }^{\circ} \mathrm{C}$ ) of $n_{s}(T)$ spectra are presented for (i) All interpolated dataset (All), (ii) 
Figures $\mathrm{S} 4$ depicts the $n_{s}$ diversity in $\log \left(n_{s, \text { ind. }}\right) / \log \left(n_{s, \text { fit }}\right)$, which represents the ratio of the individual measurements $\left(n_{s, \text { ind. }}\right)$ to the $\log$ fit line to either all data $[$ All $(\log )]$, the

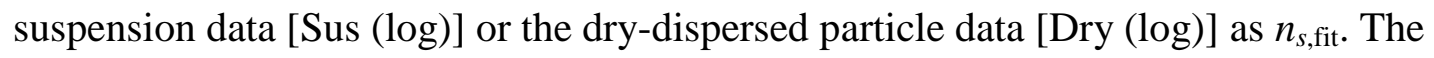
interpolated $T$-binned data (i.e., interpolated data points in Figs. 4 and 5) are used for $n_{s, \text { ind. }}$. The fit in the log space, which is derived from the parameters summarized in Table 3, is used as a denominator to avoid a bias of sudden jump of the reference value at certain temperatures where the number of available data changes. As shown in the figure, data deviation (i.e., scatter from the $\operatorname{Avg} . \log \left(n_{s, \text { ind. }}\right) / \log \left(n_{s, \text { fit }}\right)=1$ line $)$ can be seen in both suspension measurements and dry aerosol measurements. This deviation is observed with all the $n_{s, \text { fit }}$ cases [All (log), Sus (log) and Dry (log)]. Additionally, the scatter of individual non- $T$-binned data and the validity of interpolations are presented in Figs. S5-S8. In specific, these four figures (Figs. S5-S8) complement panels a.ii and a.iii, panels b.ii and b.iii, panels a.iv anda.v and panels b.iv and b.v. from Fig. S4, respectively, in greater detail.
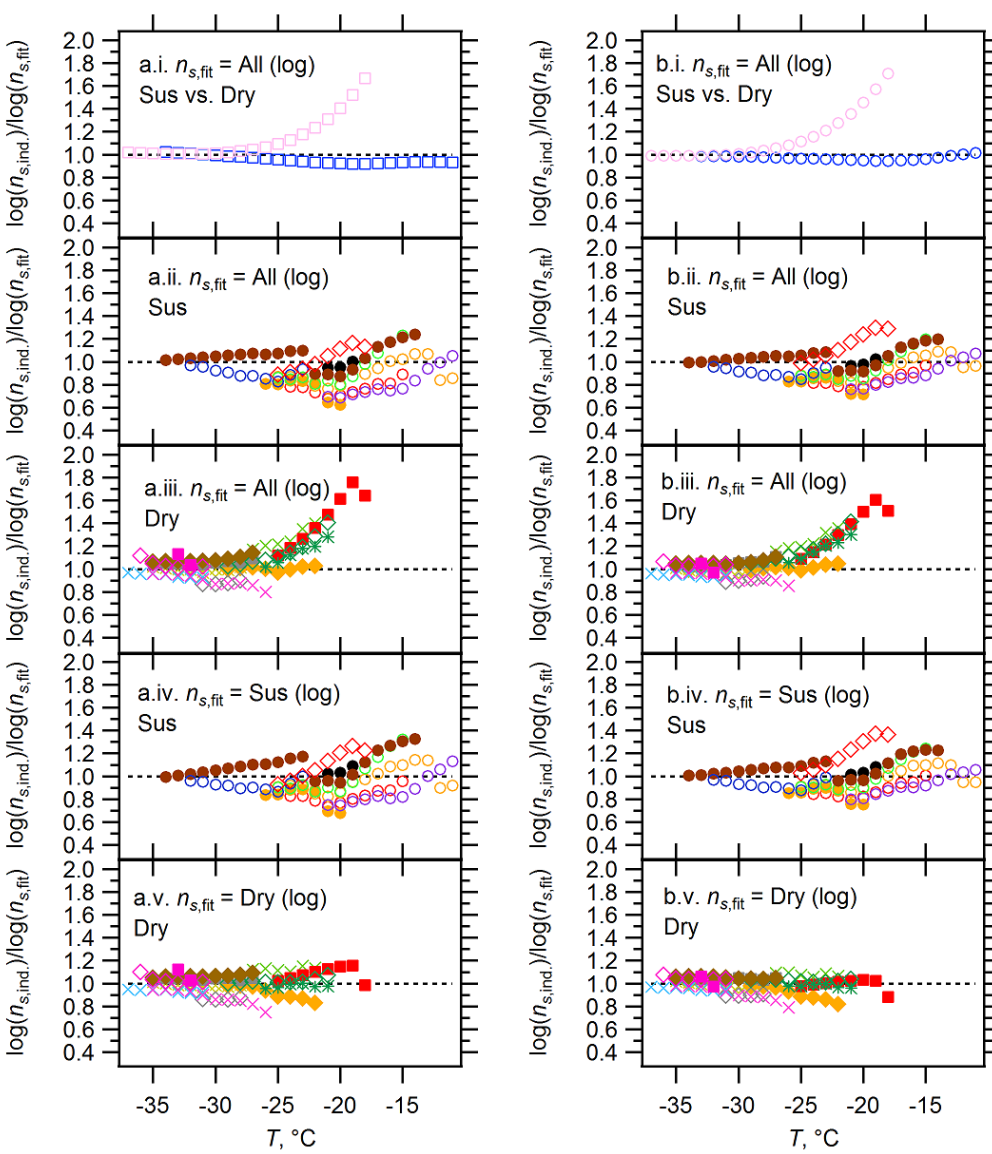

\begin{tabular}{|ll|}
\hline$\ldots .$. & $\log \left(n_{\text {s.ind. }}\right) / \log \left(n_{\text {s,fit }}\right)=1$ \\
$\square$ & Sus (BET) \\
& Dry (BET) \\
0 & Sus (geo) \\
& Dry (geo) \\
Suspension measurements \\
0 BINARY \\
0 CSU-IS (bulk) \\
CSU-IS (500 nm) \\
0 Leeds-NIPI \\
0 M-AL \\
$\bullet$ M-WT \\
NC State-CS \\
0 CU-RMCS \\
$\diamond$ FRIDGE (imm.mode) \\
Dry particle measurements \\
$\times$ AIDA (poly) \\
$\diamond$ AIDA (size-selected) \\
CSU-CFDC \\
$\diamond$ EDB (contact) \\
$\diamond$ EDB (imm.mode) \\
$\times$ FINCH \\
FRIDGE (default) \\
$\times$ LACIS \\
$*$ MRI-DCECC(poly) \\
$\diamond$ MRI-DCECC(size-selected) \\
$\times$ PINC (adjusted) \\
$\qquad$ PNNL-CIC \\
$\diamond$ ZINC \\
$\diamond$ IMCA-ZINC \\
\end{tabular}

Figure S4. T-binned ratios of the interpolated individual measurements to the fit of the data, $\log \left(n_{s, \text { ind. }}\right) / \log \left(n_{s, \text { fit }}\right)$, based on the BET (a) and geometric (b) surface area, across the temperature range covered for all the measurement techniques used in the present study (i.e., $1{ }^{\circ} \mathrm{C}$ bins for $-37{ }^{\circ} \mathrm{C}<T<-11{ }^{\circ} \mathrm{C}$ ). $T$-binned $\log \left(n_{s, \text { ind. }}\right) / \log \left(n_{s, \text { fit }}\right)$ are presented for (i) ratios of the $\log$ fit to suspension measurements [Sus (log)] or drydispersed particle measurements [Dry $(\log )]$ to the $\log$ fit to all the data [All $(\log )]$, (ii) ratios of the individual suspension measurements to All (log), (iii) ratios of the individual dry-dispersed particle measurements to All (log), (iv) ratios of the individual suspension measurements to Sus $(\log )$ and (v) ratios of the individual drydispersed particle measurements to Dry $(\log )$. The black dotted line represents $\log \left(n_{s, \text { ind. }}\right) / \log \left(n_{s, \text { fit }}\right)=1$. 


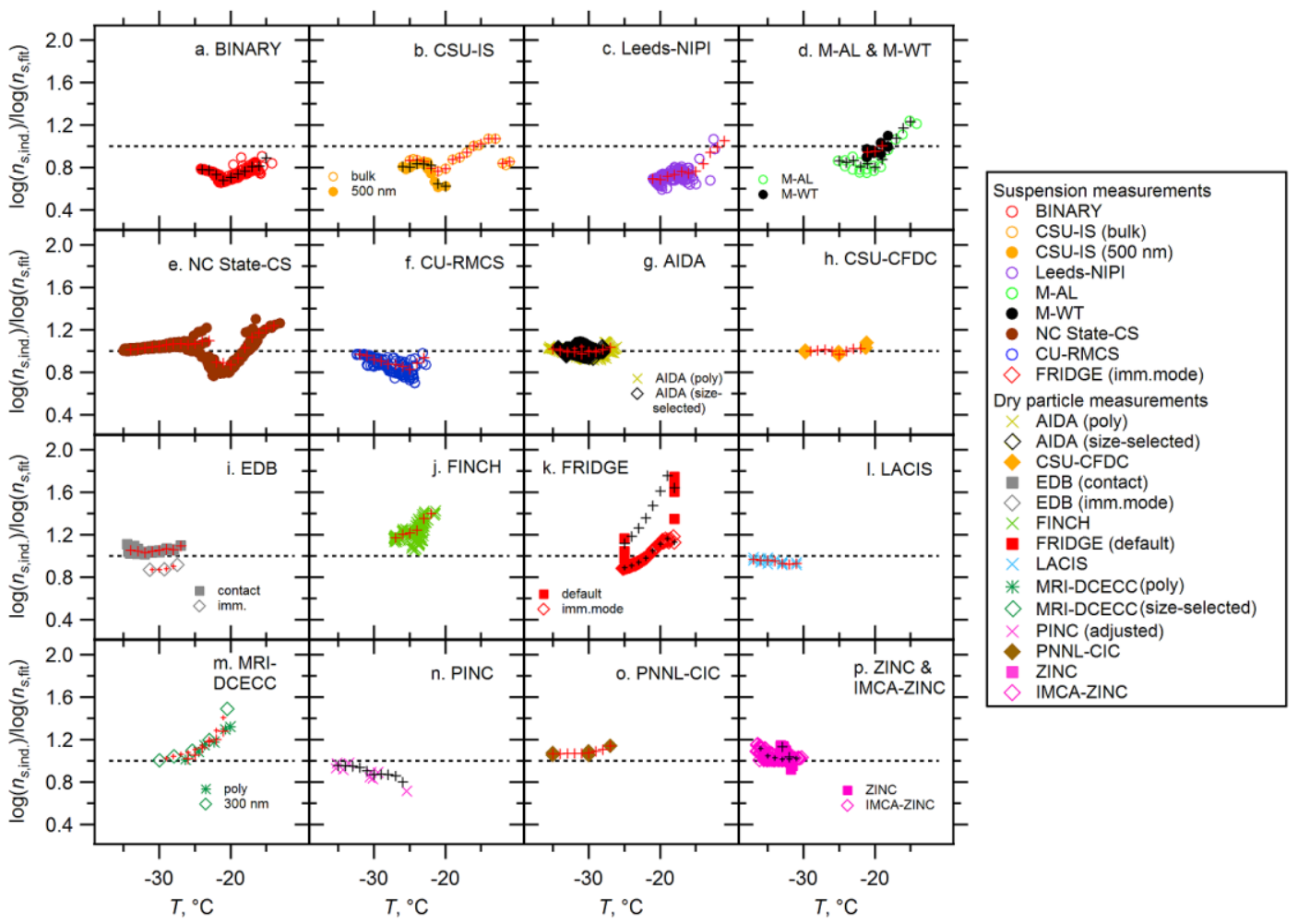

Figure S5. Ratios of the individual measurements to the log fit to all the data [All $(\log )], \log \left(n_{s, \text { ind. }}\right) / \log \left(n_{s, \text { fit }}\right)$, based on the BET surface area $\left(n_{s, \text { ind. }}=n_{s, \text { BET }}\right)$. Black or red cross markers represent $T$-binned ratios of the interpolated individual measurements to All (log) in comparison to the non- $T$-binned ratios. The black dotted line represents $\log \left(n_{s, \text { ind. }}\right) / \log \left(n_{s, \text { fit }}\right)=1$.

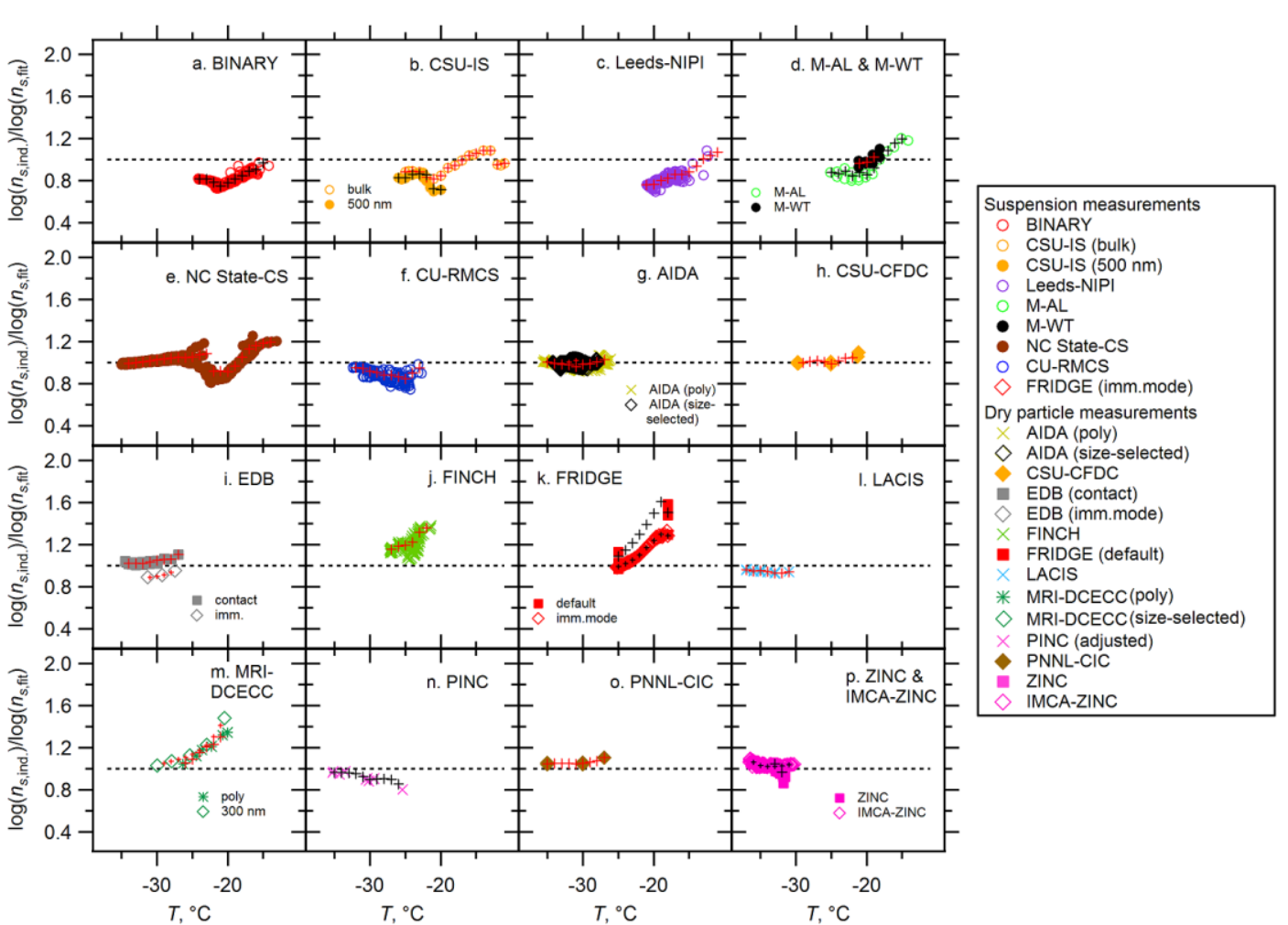

Figure S6. Ratios of the individual measurements to the $\log$ fit to all the data $[$ All $(\log )], \log \left(n_{s, \text { ind. }}\right) / \log \left(n_{s, \text { fit }}\right)$, based on the geometric surface area $\left(n_{s, \text { ind. }}=n_{s, \text { geo }}\right)$. Black or red cross markers represent $T$-binned ratios of the interpolated individual measurements to All (log) in comparison to the non- $T$-binned ratios. The black dotted line represents $\log \left(n_{s, \text { ind. }}\right) / \log \left(n_{s, \text { fit }}\right)=1$. 


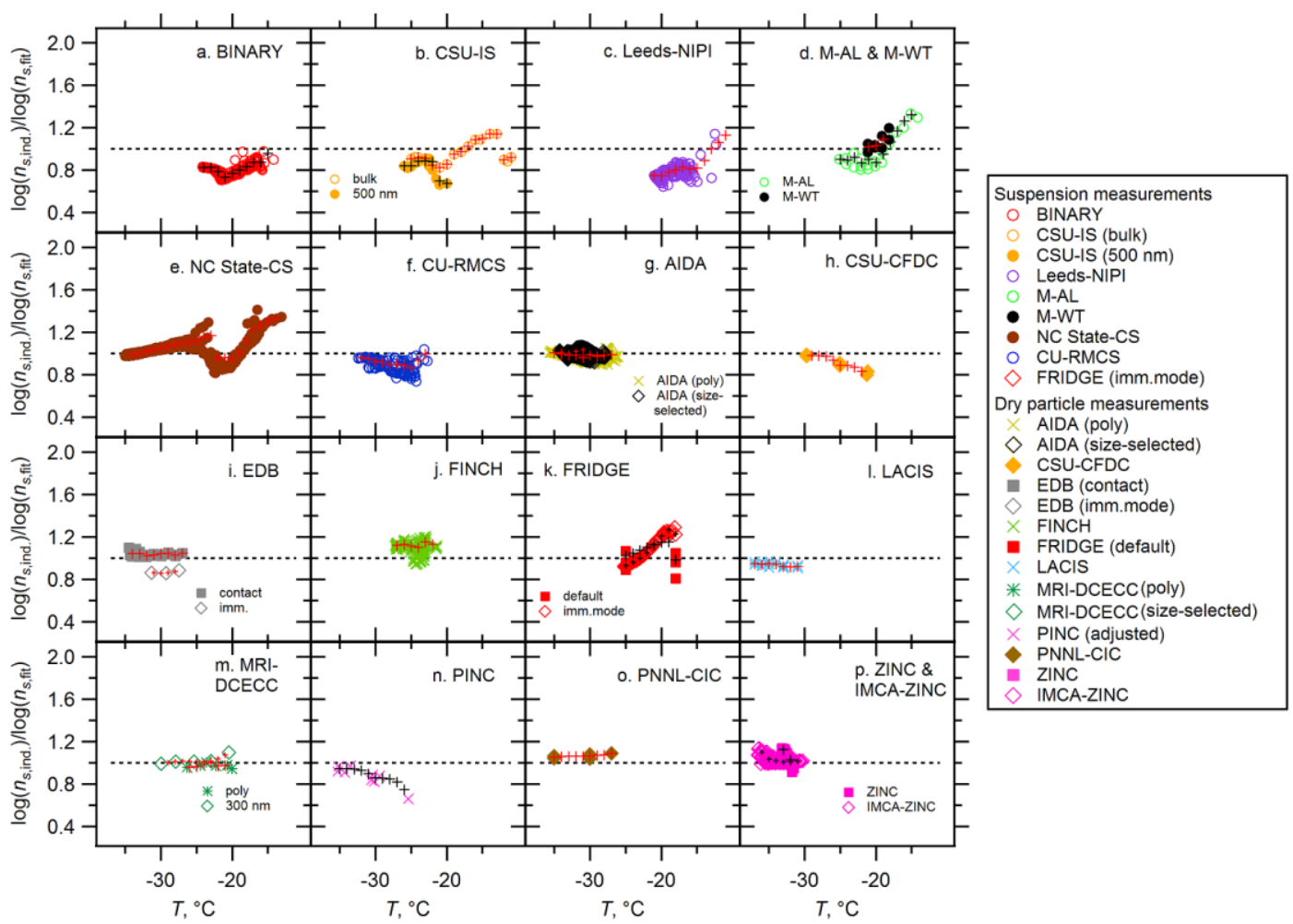

Figure S7. Ratios of the individual measurements to the log fit to suspension measurements [Sus $(\log )$ ] or drydispersed particle measurements [Dry $(\log )], \log \left(n_{s, \text { ind. }}\right) / \log \left(n_{s, \text { fit }}\right)$, based on the BET surface area $\left(n_{s, \text { ind. }}=n_{s, \text { BET }}\right)$. Black or red cross markers represent $T$-binned ratios of the interpolated individual measurements to Sus $(\log )$ or Dry $(\log )$ in comparison to the non- $T$-binned ratios. The black dotted line represents $\log \left(n_{s, \text { ind. }}\right) / \log \left(n_{s, \text { fit }}\right)=1$.

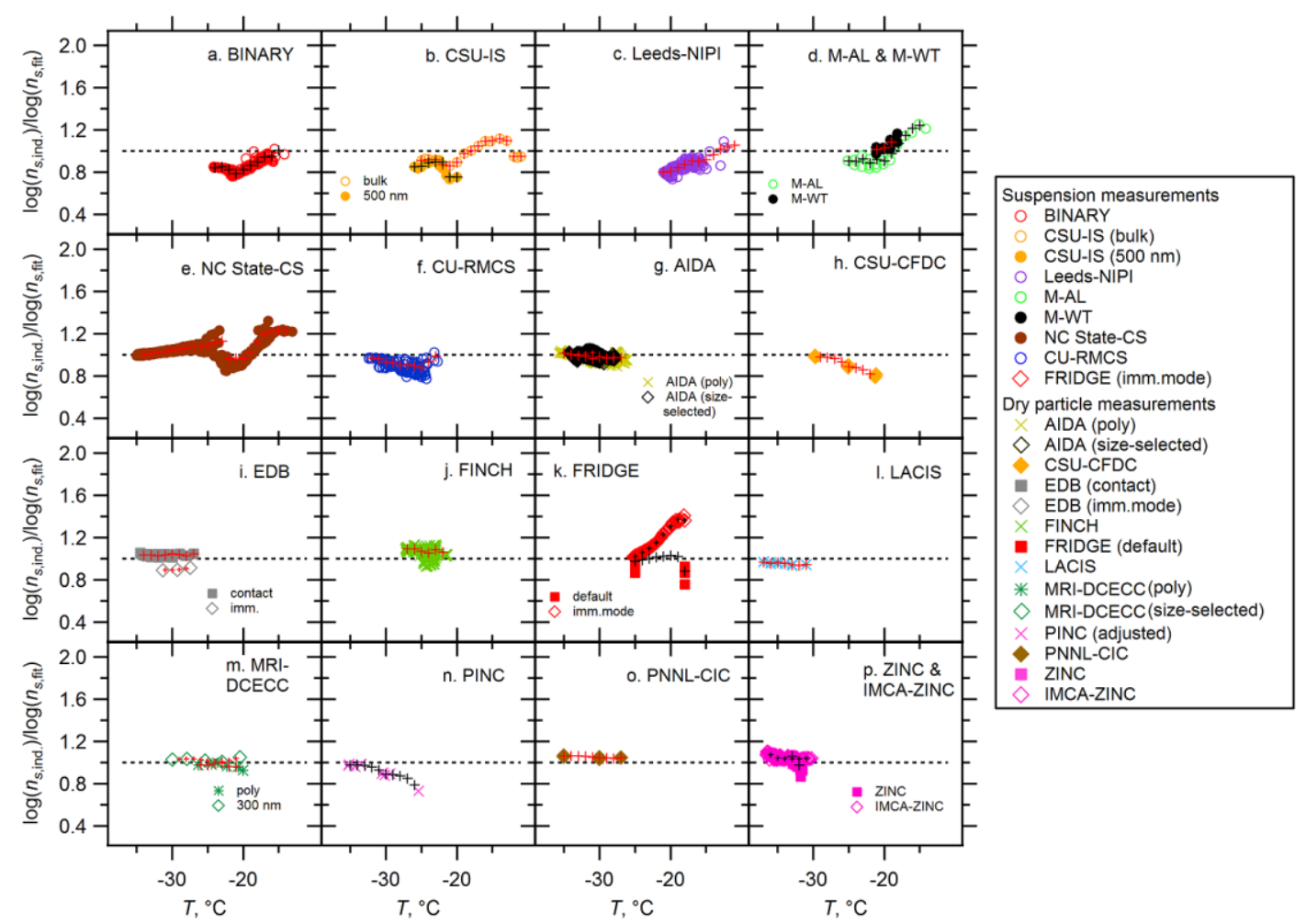

Figure S8. Ratios of the individual measurements to the log fit to suspension measurements [Sus (log)] or drydispersed particle measurements [Dry $(\log )], \log \left(n_{s, \text { ind. }}\right) / \log \left(n_{s, \text { fit }}\right)$, based on the geometric surface area $\left(n_{s, \text { ind. }}=\right.$ $n_{s, \text { geo }}$ ). Black or red cross markers represent $T$-binned ratios of the interpolated individual measurements to Sus (log) or Dry (log) in comparison to the non- $T$-binned ratios. The black dotted line represents $\log \left(n_{s, \text { ind. }}\right) / \log \left(n_{s, \text { fit }}\right)$ $=1$. 


\section{S3. Supplementary Table}

A combination of four different methods for particle dispersion (rotating brush, flask dispersion, fluidized bed, or disc-dispersion method) and four types of DMA [commercially available one from TSI (Model 3081), Type Vienna Hauke medium (Knutson and Whitby, 1975) or custom built Maxi-DMA from TROPOS (Raddatz et al., 2013)] was employed for

794

795

796

797

798

799

Table S1. Summary of methods used for dry particle generation.

\begin{tabular}{|c|c|c|c|}
\hline Instrument & Dispersion method & Size selecting instrument & Impactor type \\
\hline $\mathrm{AIDA}^{*}$ & Rotating brush & TSI DMA 3081 & $\begin{array}{l}\text { Cyclone impactors } \\
\left(D_{50} 1 \mu \mathrm{m} \text { and } 5 \mu \mathrm{m}\right)\end{array}$ \\
\hline CSU-CFDC & Flask dispersion & TSI DMA 3081 & $\begin{array}{l}\text { Dual single-jet impactors } \\
\text { (cutpoint of } 1.5 \text { and } 2.4 \mu \mathrm{m} \text { ) }\end{array}$ \\
\hline $\mathrm{EDB}^{*}$ & Fluidized bed & TSI DMA 3081 & $\begin{array}{l}\text { Multistage impactor } \\
\text { (cutpoint of } 2 \mu \mathrm{m} \text { ) }\end{array}$ \\
\hline $\mathrm{FINCH}^{*}$ & Fluidized bed & $\begin{array}{l}\text { DMA, type Vienna Hauke } \\
\text { medium }\end{array}$ & $\begin{array}{l}\text { MOUDI and cyclone } \\
\text { impactors }\end{array}$ \\
\hline $\begin{array}{l}\text { FRIDGE } \\
\text { (default) }^{*}\end{array}$ & Rotating brush & TSI DMA 3081 & $\begin{array}{l}\text { Cyclone impactors } \\
\left(D_{50} 1 \mu \mathrm{m} \text { and } 5 \mu \mathrm{m}\right)\end{array}$ \\
\hline LACIS $^{*}$ & Fluidized bed & $\begin{array}{l}\text { DMA, type Vienna Hauke } \\
\text { medium }\end{array}$ & $\begin{array}{l}\text { MOUDI and cyclone } \\
\text { impactors }\end{array}$ \\
\hline MRI-DCECC & Rotating brush & TSI DMA 3081 & $\begin{array}{c}\text { Cyclone impactors } \\
\left(D_{50} \text { of } 2.5 \mu \mathrm{m} \text { and } 1.0 \mu \mathrm{m}\right)\end{array}$ \\
\hline PINC & Rotating brush & TROPOS Maxi-DMA & $\begin{array}{c}\text { Impactor } \\
\left(D_{50} \text { at } 0.91 \mu \mathrm{m}\right)\end{array}$ \\
\hline PNNL-CIC & Rotating disc dispersion & TSI DMA 3081 & $\begin{array}{l}\text { Cyclone impactor } \\
\quad\left(D_{50} \sim 1 \mu \mathrm{m}\right)\end{array}$ \\
\hline IMCA-ZINC & Fluidized bed & TSI DMA 3081 & $\begin{array}{l}\text { Cyclone impactors } \\
\left(D_{50} 3 \mu \mathrm{m} \text { and } 1 \mu \mathrm{m}\right)\end{array}$ \\
\hline
\end{tabular}
particle generation of illite NX samples. Further, most of the dry dispersion techniques used upstream impactors to filter out large agglomerated particles and safeguard against counting these large particles as INPs. The different types of dispersion methods, impactors and size segregating instruments used in the present work are listed below.

Instruments of INUIT project partners. 
S4. List of Abbreviations, Acronyms and Symbols (Alphabetical Order)

802

AIDA: $\quad$ Aerosol Interaction and Dynamics in the Atmosphere

All (lin): multiple exponential fit to $T$-binned ensemble $n_{s}$ dataset fitted in the linear space

All (log): $\quad$ multiple exponential fit to $T$-binned ensemble $n_{s}$ dataset fitted in the log space

All $\max$ :

All $\min :$

APS:

ATD:

A13:

BET:

BINARY:

B12:

CEC:

CECC:

CFDC:

$c_{\text {impurities }}(T)$ :

$c_{\mathrm{IN}}(T)$ :

CNT:

CPC:

CSU-IS:

CSU-CFDC: CU-RMCS:

DCECC:

DFG:

$\Delta \log \left(n_{s}\right) / \Delta T$ :

DLS:

DMA:

DSF:

$D$ :

Dry (lin):

Dry $(\log )$ :

$D_{\text {thresh: }}$

$D_{\text {ve: }}$ :

$D_{50}$ :

$D_{95}$ :

$e_{\mathrm{c}}$ :

EDB:

EDX:

FINCH:

FRIDGE:

$f:$

$f_{\text {ice: }}$

$f_{\text {ice }}^{*}$ :

$f_{\text {unfrozen }}$ :

multiple exponential fit to $T$-binned ensemble maximum $n_{s}$ values

multiple exponential fit to $T$-binned ensemble minimum $n_{s}$ values

aerodynamic particle sizer

Arizona Test Dust

Atkinson's parameterization

Brunauer, Emmett, and Teller

Bielefeld Ice Nucleation ARraY

Broadley's parameterization

Cation Exchange Capacity

controlled expansion cloud-simulation chamber

continuous flow diffusion chamber

concentration of impurities per unit volume water at temperature $T$

concentration of INP per unit volume water at temperature $T$

classical nucleation theory

condensation particle counter

Colorado State University Ice Spectrometer

Colorado State University Continuous Flow Diffusion Chamber

University of Colorado Raman microscope cold stage

Dynamic Controlled Expansion Cloud-simulation Chamber

Deutsche Forschungsgemeinschaft (German Research Society)

slope of $n_{s}(T)$ spectrum

dynamic light scattering

differential mobility analyzer

dynamic shape factor

average median diameter

multiple exponential fit to $T$-binned dry-dispersed particle $n_{s}$ subset fitted in the linear space

multiple exponential fit to $T$-binned dry-dispersed particle $n_{s}$ subset fitted in the log space

droplet-ice threshold diameter

volume equivalent midpoint diameter of individual particle

cut size with a $50 \%$ mass of particles

cut size with a $95 \%$ mass of particles

probability of freezing on a single contact

ElectroDynamic Balance

energy dispersive X-ray

Fast Ice Nucleus CHamber

FRankfurt Ice Deposition freezinG Experiment

proportion of droplets not frozen

frozen fraction after time $t$

fraction of droplets frozen

fraction of unfrozen drops at each particular temperature 
Hor Max-Min: horizontal $T$ deviation between maxima and minima in $n_{s}(T)$ spectrum IC: $\quad$ ion chromatography

851 ICIS-2007: international ice nucleation workshop in 2007

852 illite NX: commercially available NX Nanopowder illite-rich dust from Arginotec

853 IMCA-ZINC: Zurich Ice Nucleation Chamber with Immersion Mode Cooling-chAmber

854 IN ice nucleation

855 INP: ice-nucleating particle

856 INUIT: Ice Nuclei research UnIT

857 IODE: Ice Optical DEpolarization detector

858 K-feldspar: potassium-rich feldspar

$859 K^{\prime}(T)$ : $\quad$ cumulative INP concentration at a temperature $T$

860 LACIS: $\quad$ Leipzig Aerosol Cloud Interaction Simulator

861 Leeds-NIPI: Leeds Nucleation by Immersed Particles Instrument

$862 \log \left(n_{s, \text { ind. }}\right) / \log \left(n_{s, \text { it }}\right)$ :

863 ratios of the individual measurements to the fit of the data

864 M-AL: $\quad$ Mainz Acoustic Levitator

865 M-WT: Mainz vertical Wind Tunnel

866 min: minute

867 MRI-DCECC: Meteorological Research Institute DCECC

$868 M_{\text {total }}: \quad$ total mass concentration of particles

$869 \quad M_{\mathrm{ve}}: \quad$ volume equivalent mass of individual particle

$870 \quad n_{\mathrm{c}}: \quad$ collision rate

871 NC State-CS: North Carolina State cold stage

$872 \quad N_{\mathrm{ae}}$ : number concentration of aerosols

$873 \quad N_{\text {droplet: }} \quad$ number concentration of droplets

$874 \quad N_{\text {ice }}: \quad$ number concentration of ice crystals

$875 \quad n_{m, \text { geo }}$ geometric mass-based ice-nucleating mass

$876 n_{m, \text { sus }}$ : ice-nucleating mass derived from suspension measurements

$877 \quad n_{s}: \quad$ IN active surface-site density

$878 n_{s, \text { average: }} \quad$ average $n_{s}$

$879 \quad n_{s, \mathrm{BET}}: \quad$ BET surface-inferred $n_{s}$

$880 \quad n_{s, \text { ind. }}$ : individual $n_{s}$ measurements

$881 n_{s, \text { fit }}: \quad$ fit of all the $n_{s, \text { ind. }}$ data across the measured temperature range

$882 \quad n_{s, \text { geo: }} \quad$ geometric size based $n_{s}$

$883 \quad n_{s, \max }: \quad$ maximum $n_{s}$

$884 \quad n_{s, \min }: \quad$ minimum $n_{s}$

$885 N(T): \quad$ number of frozen droplets at temperature $T$

$886 \quad N_{\text {total }}: \quad$ total number concentration of particles

$887 \quad N_{0}: \quad$ total number of droplets

888 N12: Niemand's parameterization

889 OPC: $\quad$ optical particle counter

890 OPS: $\quad$ optical particle sizer

891 PCR: $\quad$ polymerase chain reaction

892 PDF: probability density function

893 PDMS: polydimethylsiloxane

894 PINC: $\quad$ Portable Ice Nucleation Chamber

895 PNNL-CIC: Pacific Northwest National Laboratory Compact Ice Chamber

$896 \quad r: \quad$ correlation coefficient

$897 \mathrm{RH}_{\text {ice: }} \quad$ relative humidity with respect to ice

$898 \mathrm{RH}_{\mathrm{w}}$ : $\quad$ relative humidity with respect to water

$899 \mathrm{RH}_{\mathrm{w}, \mathrm{ds}}: \quad \mathrm{RH}_{\mathrm{w}}$ at which droplets survive past the evaporation section 


\begin{tabular}{|c|c|c|}
\hline 900 & s: & second \\
\hline 901 & SBM: & soccer ball model \\
\hline 902 & SIMONE: & German acronym of Streulicht-intensitätsmessungen zum optischen Nachweis \\
\hline 03 & & von Eispartikeln, which translates to the scattering intensity measurement for \\
\hline 904 & & the optical detection of ice \\
\hline 905 & $S_{\mathrm{IN}}:$ & surface area of a single ice-nucleating particle \\
\hline 906 & SMPS: & scanning mobility particle sizer \\
\hline 907 & SSA: & specific surface area \\
\hline 908 & SSPD: & small-scale powder disc-disperser \\
\hline 909 & $S_{\text {total }}:$ & total surface area concentration of particles \\
\hline 910 & Sus (lin): & multiple exponential fit to $T$-binned suspension $n_{s}$ subset fitted in the linear \\
\hline 911 & & space \\
\hline 912 & Sus (log): & multiple exponential fit to $T$-binned suspension $n_{s}$ subset fitted in the log space \\
\hline 913 & $S_{\mathrm{ve}}:$ & volume equivalent surface area of individual particle \\
\hline 914 & $t:$ & time \\
\hline 915 & $T:$ & temperature \\
\hline 916 & $T$-binned Lin. & Avg.: \\
\hline 917 & & multiple exponential distribution fit to the $T$-binned average data in the linear \\
\hline 18 & & space \\
\hline 919 & T-binned Log. & Avg: \\
\hline 920 & & multiple exponential distribution fit to the $T$-binned average data in the log \\
\hline 921 & & space \\
\hline 922 & $T$-binned Max & x.: fit to the $T$-binned maxima in the linear space \\
\hline 923 & T-binned Min. & 1.: fit to the $T$-binned minima in the linear space \\
\hline 924 & TDL: & tunable diode laser \\
\hline 925 & $T_{\text {drop }}(t):$ & drop surface temperature \\
\hline 926 & $T_{\text {droplet,onset: }}$ & droplet onset temperature \\
\hline 927 & TROPOS: & Leibniz Institute for Tropospheric Research \\
\hline 928 & UHSAS: & Ultra-High Sensitivity Aerosol Spectrometer \\
\hline 929 & $V:$ & droplet volume \\
\hline 930 & $V_{\text {drop: }}$ & median drop volume of the population \\
\hline 931 & Ver Max-Min: & vertical $n_{s}$ deviation between maxima and minima in $n_{s}(T)$ spectrum \\
\hline 932 & $w:$ & mass ratio of dust and water ( $\mathrm{g}$ dust/g water) \\
\hline 933 & wt\%: & weight percent \\
\hline 934 & $x:$ & volume of water used to wash the particles from the filter \\
\hline 935 & XRD: & X-ray diffraction \\
\hline 936 & $y:$ & volume of air sampled through the filter \\
\hline 937 & $\alpha:$ & ice activated fraction $\left(=N_{\text {ice }} / N_{\text {total }}\right)$ \\
\hline 938 & $\theta:$ & specific surface area measured by BET technique \\
\hline 939 & $\theta_{\mathrm{N} 2}:$ & specific surface area measured by BET technique with nitrogen gas \\
\hline 940 & $\theta_{\mathrm{H} 2 \mathrm{O}}:$ & specific surface area measured by BET technique with water vapor \\
\hline 941 & $\rho:$ & particle density of illite NX \\
\hline 942 & $\rho_{\mathrm{w}}:$ & density of water $\left(0.9971 \mathrm{~g} \mathrm{H}_{2} \mathrm{O} / \mathrm{m}^{3} \mathrm{H}_{2} \mathrm{O}\right)$ \\
\hline 943 & $\chi:$ & dynamic shape factor \\
\hline
\end{tabular}


945

946

Additional supplementary information is available in the online version of the paper. A

947 publically accessible data base is available at http://imk-aaf-s1.imk-aaf.kit.edu/inuit/.

948 Correspondence and requests (including readme files and access information to the database)

949 for materials should be addressed to N. Hiranuma (seong.moon@kit.edu). 


\section{References}

951

952

953

954

955

956

957

958

959

960

961

962

963

964

965

966

967

968

969

970

971

972

973

974

975

976

977

978

979

980

981

982

983

984

985

986

987

988

989

990

991

992

993

994

995

996

997
Agresti, A. and Coull, B. A.: Approximate is better than "exact" for interval estimation of binomial proportions. Am. Stat., 52, 119-126, doi:10.2307/2685469, 1998.

Ardon-Dryer, K. and Levin, Z.: Ground-based measurements of immersion freezing in the eastern Mediterranean, Atmos. Chem. Phys., 14, 5217-5231, doi:10.5194/acp-14-5217-2014, 2014.

Atkinson, J. D., Murray, B. J., Woodhouse, M. T., Carslaw, K., Whale, T. F., Baustian, K., Dobbie, S., O’Sullivan, D., and Malkin, T. L.: Nature, 498, 355-358, doi:10.1038/nature12278, 2013.

Baustian, K. J., Wise, M. E., and Tolbert, M. A.: Depositional ice nucleation on solid ammonium sulfate and glutaric acid particles, Atmos. Chem. Phys., 10, 2307-2317, doi:10.5194/acp-10-2307-2010, 2010.

Benz, S., Megahed, K., Möhler, O., Saathoff, H., Wagner, R., and Schurath, U.: T-dependent rate measurements of homogeneous ice nucleation in cloud droplets using a large atmospheric simulation chamber, J. Photoch. Photobio. A, 176, 208-217, doi:10.1016/j.jphotochem.2005.08.026, 2005.

Broadley, S. L., Murray, B. J., Herbert, R. J., Atkinson, J. D., Dobbie, S., Malkin, T. L., Condliffe, E., and Neve, L.: Immersion mode heterogeneous ice nucleation by an illite rich powder representative of atmospheric mineral dust, Atmos. Chem. Phys., 12, 287-307, doi:10.5194/acp-12-287-2012, 2012.

Budke, C. and Koop, T.: BINARY: an optical freezing array for assessing temperature and time dependence of heterogeneous ice nucleation, Atmos. Meas. Tech. Discuss., 7, 91379172, doi:10.5194/amtd-7-9137-2014, 2014.

Bundke, U., Nillius, B., Jaenicke, R., Wetter, T., Klein, H., and Bingemer, H.: The fast ice nucleus chamber FINCH, Atmos. Res., 90, 180-186, doi:10.1016/j.atmosres.2008.02.008, 2008.

Bundke, U., Reimann, B., Nillius, B., Jaenicke, R., and Bingemer, H.: Development of a Bioaerosol single particle detector (BIO IN) for the Fast Ice Nucleus CHamber FINCH, Atmos. Meas. Tech., 3, 263-271, doi:10.5194/amt-3-263-2010, 2010.

Chou, C., Stetzer, O.,Weingartner, E., Jurányi, Z., Kanji, Z. A., and Lohmann, U.: Ice nuclei properties within a Saharan dust event at the Jungfraujoch in the Swiss Alps, Atmos. Chem. Phys., 11, 4725-4738, doi:10.5194/acp-11-4725-2011, 2011.

Clauss, T., Kiselev, A., Hartmann, S., Augustin, S., Pfeifer, S., Niedermeier, D., Wex, H., and Stratmann, F.: Application of linear polarized light for the discrimination of frozen and liquid droplets in ice nucleation experiments, Atmos. Meas. Tech., 6, 1041-1052, doi:10.5194/amt6-1041-2013, 2013. 
DeMott, P. J. and Coauthors: Resurgence in ice nuclei measurement research, B. Am. Meteorol. Soc., 92, 1623-1635, doi:http://dx.doi.org/10.1175/2011BAMS3119.1, 2011.

DeMott, P. J., Prenni, A. J., McMeeking, G. R., Sullivan, R. C., Petters, M. D., Tobo, Y., Niemand, M., Möhler, O., Snider, J. R., Wang, Z., and Kreidenweis, S. M.: Integrating laboratory and field data to quantify the immersion freezing ice nucleation activity of mineral dust particles, Atmos. Chem. Phys. Discuss., 14, 17359-17400, doi:10.5194/acpd-14-173592014, 2014.

Diehl, K., Mitra, S. K., Szakáll, M., Blohn, N. v., Borrmann, S., and Pruppacher, H.R.: Chapter 2. Wind Tunnels: Aerodynamics, Models, and Experiments. In: The Mainz Vertical Wind Tunnel Facility: A Review of 25 Years of Laboratory Experiments on Cloud Physics and Chemistry [Pereira, J. D. (eds.)], Nova Science Publishers, Inc., Hauppauge, NY, USA, 2011.

Diehl, K., Debertshäuser, M., Eppers, O., Schmithüsen, H., Mitra, S.K., and Borrmann, S.: Particle-area dependence of mineral dust in the immersion mode: investigations with freely suspended drops in an acoustic levitator. Atmos. Chem. Phys., 14, 12343-12355, doi:10.5194/acp-14-12343-2014, 2014.

Eidhammer, T., DeMott, P. J., Prenni, A. J., Petters, M. D., Twohy, C. H., Rogers, D. C., Stith, J., Heymsfield, A., Wang, Z., Haimov, S., French, J., Pratt, K., Prather, K., Murphy, S., Seinfeld, J., Subramanian, R., and Kreidenweis, S. M.: Ice initiation by aerosol particles: Measured and predicted ice nuclei concentrations versus measured ice crystal concentrations in an orographic wave cloud. J. Atmos. Sci., 67, 2417-2436. doi: 10.1175/2010JAS3266.1, 2010 .

Fahey, D. W., Gao, R.-S., Möhler, O., Saathoff, H., Schiller, C., Ebert, V., Krämer, M., Peter, T., Amarouche, N., Avallone, L. M., Bauer, R., Bozóki, Z., Christensen, L. E., Davis, S. M., Durry, G., Dyroff, C., Herman, R. L., Hunsmann, S., Khaykin, S. M., Mackrodt, P., Meyer, J., Smith, J. B., Spelten, N., Troy, R. F., Vömel, H., Wagner, S., and Wienhold, F. G.: The AquaVIT-1 intercomparison of atmospheric water vapor measurement techniques, Atmos. Meas. Tech. Discuss., 7, 3159-3251, doi:10.5194/amtd-7-3159-2014, 2014.

Friedman, B., Kulkarni, G., Beránek, J., Zelenyuk, A., Thornton, J. A., and Cziczo, D. J.: Ice nucleation and droplet formation by bare and coated soot particles, J. Geophys. Res., 116, D17203, doi:10.1029/2011JD015999, 2011.

Hader, J. D., Wright, T. P., and Petters, M. D.: Contribution of pollen to atmospheric ice nuclei concentrations, Atmos. Chem. Phys., 14, 5433-5449, doi:10.5194/acp-14-5433-2014, 2014.

Hartmann, S., Niedermeier, D., Voigtländer, J., Clauss, T., Shaw, R. A., Wex, H., Kiselev, A., and Stratmann, F.: Homogeneous and heterogeneous ice nucleation at LACIS: operating principle and theoretical studies, Atmos. Chem. Phys., 11, 1753-1767, doi:10.5194/acp-111753-2011, 2011.

Herbert, R. J., Murray, B. J., Whale, T. F., Dobbie, S. J., and Atkinson, J. D.: Representing time-dependent freezing behaviour in immersion mode ice nucleation, Atmos. Chem. Phys., 14, 8501-8520, doi:10.5194/acp-14-8501-2014, 2014. 
Hiranuma, N., Paukert, M., Steinke, I., Zhang, K., Kulkarni, G., Hoose, C., Schnaiter, M., Saathoff, H., and Möhler, O.: A comprehensive parameterization of heterogeneous ice nucleation of dust surrogate: laboratory study with hematite particles and its application to atmospheric models, Atmos. Chem. Phys., 14, 13145-13158, doi:10.5194/acp-14-131452014, 2014a.

Hiranuma, N., Hoffmann, N., Kiselev, A., Dreyer, A., Zhang, K., Kulkarni, G., Koop, T., and Möhler, O.: Influence of surface morphology on the immersion mode ice nucleation efficiency of hematite particles, Atmos. Chem. Phys., 14, 2315-2324, doi:10.5194/acp-142315-2014, 2014b.

Hoffmann, N., Duft, D., Kiselev, A., and Leisner, T.: Contact freezing efficiency of mineral dust aerosols studied in an electrodynamic balance: quantitative size and temperature dependence for illite particles, Faraday Discuss., 165, 383-390, doi:10.1039/C3FD00033H, 2013a.

Hoffmann, N., Kiselev, A., Rzesanke, D., Duft, D., and Leisner, T.: Experimental quantification of contact freezing in an electrodynamic balance, Atmos. Meas. Tech., 6, 23732382, doi:10.5194/amt-6-2373-2013, 2013b.

Hu, Y.-X., Yang, P., Lin, B., Gibson, G., Hostetler, C.: Discriminating between spherical and non-spherical scatterers with lidar using circular polarization: a theoretical study. J. Quant. Spectrosc. Radiat. Transfer, 79-80, 757-764, doi:10.1016/S0022-4073(02)00320-5, 2003.

Kanji, Z. A., Welti, A., Chou, C., Stetzer, O., and Lohmann, U.: Laboratory studies of immersion and deposition mode ice nucleation of ozone aged mineral dust particles, Atmos. Chem. Phys., 13, 9097-9118, doi:10.5194/acp-13-9097-2013, 2013.

Klein, H., Haunold, W., Bundke, U., Nillius, B., Wetter, T., Schallenberg, S., and Bingemer, H.: A new method for sampling of atmospheric ice nuclei with subsequent analysis in a static diffusion chamber, Atmos. Res., 96, 218-224, doi:10.1016/j.atmosres.2009.08.002, 2010.

Knutson, E. O., and Whitby, K. T.: Aerosol classification by electric mobility: apparatus, theory, and applications. Aerosol Sci., 6, 6, 443-451, doi:10.1016/0021-8502(75)90060-9, 1975.

Kulkarni, G., Fan, J., Comstock, J. M., Liu, X., and Ovchinnikov, M.: Laboratory measurements and model sensitivity studies of dust deposition ice nucleation, Atmos. Chem. Phys., 12, 7295-7308, doi:10.5194/acp-12-7295-2012, 2012.

Langham, E. J. and Mason, B. J.: The heterogeneous and homogeneous nucleation of supercooled water. Proceedings of the Royal Society A: Mathematical, Physical and Engineering Sciences, 247, 1251, 493-504. doi:10.1098/rspa.1958.0207, 1958.

Lüönd, F., Stetzer, O., Welti, A., and Lohmann, U.: Experimental study on the ice nucleation ability of size-selected kaolinite particles in the immersion mode, J. Geophys. Res., 115, D14201, doi:10.1029/2009JD012959, 2010.

Möhler, O., Stetzer, O., Schaefers, S., Linke, C., Schnaiter, M., Tiede, R., Saathoff, H., Krämer, M., Mangold, A., Budz, P., Zink, P., Schreiner, J., Mauersberger, K., Haag, W., Kärcher, B., and Schurath, U.: Experimental investigation of homogeneous freezing of 
sulphuric acid particles in the aerosol chamber AIDA, Atmos. Chem. Phys., 3, 211-223, doi:10.5194/acp-3-211-2003, 2003.

Möhler, O., Field, P. R., Connolly, P., Benz, S., Saathoff, H., Schnaiter, M., Wagner, R., Cotton, R., Krämer, M., Mangold, A., and Heymsfield, A. J.: Efficiency of the deposition mode ice nucleation on mineral dust particles, Atmos. Chem. Phys., 6, 3007-3021, doi:10.5194/acp-6-3007-2006, 2006.

Murphy, D. M., and Koop, T.: Review of the vapour pressures of ice and supercooled water for atmospheric applications, Q. J. R. Meteorol. Soc., 131, 1539-1565, doi:10.1256/qj.04.94, 2005.

Murray, B. J., Broadley, S. L., Wilson, T. W., Atkinson, J. D., and Wills, R. H.:

Heterogeneous freezing of water droplets containing kaolinite particles, Atmos. Chem. Phys., 11, 4191-4207, doi:10.5194/acp-11-4191-2011, 2011.

Murray, B. J., O’Sullivan, D., Atkinson, J. D., and Webb, M. E.: Ice nucleation by particles immersed in supercooled cloud droplets, Chem. Soc. Rev., 41, 6519-6554, doi:10.1039/c2cs35200a, 2012.

Nicolet, M., Stetzer, O., Lüönd, F., Möhler, O., and Lohmann, U.: Single ice crystal measurements during nucleation experiments with the depolarization detector IODE, Atmos. Chem. Phys., 10, 313-325, doi:10.5194/acp-10-313-2010, 2010.

O’Sullivan, D., Murray, B. J., Malkin, T. L., Whale, T. F., Umo, N. S., Atkinson, J. D., Price, H. C., Baustian, K. J., Browse, J., and Webb, M. E.: Ice nucleation by fertile soil dusts: relative importance of mineral and biogenic components, Atmos. Chem. Phys., 14, 18531867, doi:10.5194/acp-14-1853-2014, 2014.

Petters, M. D., Parsons, M. T., Prenni, A. J., DeMott, P. J., Kreidenweis, S. M., Carrico, C. M., Sullivan, A. P., McMeeking, G. R., Levin, E., Wold, C. E., Collett, J. L. Jr., and Moosmüller, H.: Ice nuclei emissions from biomass burning, J. Geophys. Res., 114, D07209, doi:10.1029/2008JD011532, 2009.

Prenni, A. J., DeMott, P. J., Rogers, D. C., Kreidenweis, S. M., McFarquhar, G. M., Zhang, G., and Poellot, M. R.: Ice nuclei characteristics from M-PACE and their relation to ice formation in clouds, Tellus, 61B, 436-448, doi:10.1111/j.1600-0889.2009.00415.x, 2009.

Raddatz, M., Wiedensohler, A., Wex, H., and Stratmann, F.: Size selection of sub- and supermicron clay mineral kaolinite particles using a custom-built Maxi-DMA, AIP Conference Proceedings, 1527, 457-460, 2013.

Richardson, M.: Making real time measurements of ice nuclei concentrations at upper tropospheric temperatures: Extending the capabilities of the continuous flow diffusion chamber, DISSERTATION thesis, Colorado State Univ., Fort Collins, CO, USA, 268 pp, 2009.

Rzesanke, D., Nadolny, J., Duft, D., Muller, R., Kiselev, A., and Leisner, T.: On the role of surface charges for homogeneous freezing of supercooled water microdroplets, Phys. Chem. Chem. Phys., 14, 9359-9363, doi:10.1039/c2cp23653b, 2012. 
Rogers, D. C.: Development of a continuous flow thermal gradient diffusion chamber for ice nucleation studies, Atmos. Res., 22, 149-181, doi:10.1016/0169-8095(88)90005-1, 1988.

Rogers, D. C., DeMott, P. J., Kreidenweis, S. M., and Chen, Y.: A continuous-flow diffusion chamber for airborne measurements of ice nuclei, J. Atmos. Oceanic Technol., 18, 725-741, doi:http://dx.doi.org/10.1175/1520-0426(2001)018<0725:ACFDCF>2.0.CO;2, 2001.

Schill, G. P. and Tolbert, M. A.: Heterogeneous ice nucleation on phase-separated organicsulfate particles: effect of liquid vs. glassy coatings, Atmos. Chem. Phys., 13, 4681-4695, doi:10.5194/acp-13-4681-2013, 2013.

Schnaiter, M., Büttner, S., Möhler, O., Skrotzki, J., Vragel, M., and Wagner, R.: Influence of particle size and shape on the backscattering linear depolarisation ratio of small ice crystals cloud chamber measurements in the context of contrail and cirrus microphysics, Atmos.

Chem. Phys., 12, 10465-10484, doi:10.5194/acp-12-10465-2012, 2012.

Steinke, I., Möhler, O., Kiselev, A., Niemand, M., Saathoff, H., Schnaiter, M., Skrotzki, J., Hoose, C., and Leisner, T.: Ice nucleation properties of fine ash particles from the Eyjafjallajökull eruption in April 2010, Atmos. Chem. Phys., 11, 12945-12958, doi:10.5194/acp-11-12945-2011, 2011.

Stetzer, O., Baschek, B., Luond, F., and Lohmann, U.: The Zurich Ice Nucleation Chamber (ZINC) - A new instrument to investigate atmospheric ice formation, Aerosol Sci. Technol., 42, 64-74, doi:10.1080/02786820701787944, 2008.

Sullivan, R. C., Petters, M. D., DeMott, P. J., Kreidenweis, S. M., Wex, H., Niedermeier, D., Hartmann, S., Clauss, T., Stratmann, F., Reitz, P., Schneider, J., and Sierau, B.: Irreversible loss of ice nucleation active sites in mineral dust particles caused by sulphuric acid condensation, Atmos. Chem. Phys., 10, 11471-11487, doi:10.5194/acp-10-11471-2010, 2010a.

Sullivan, R. C., Miñambres, L., DeMott, P. J., Prenni, A. J., Carrico, C. M., Levin, E. J. T., and Kreidenweis, S. M.: Chemical processing does not always impair heterogeneous ice nucleation of mineral dust particles, Geophys. Res. Lett., 37, L24805, doi:10.1029/2010GL045540, 2010b.

Szakáll, M., Diehl, K., Mitra, S. K., and Borrmann, S.: A wind tunnel study on the shape, oscillation, and internal circulation of large raindrops with sizes between 2.5 and $7.5 \mathrm{~mm}, \mathrm{~J}$. Atmos. Sci., 66, 755-765, doi:http://dx.doi.org/10.1175/2008JAS2777.1, 2009.

Tajiri, T., Yamashita, K., Murakami, M., Orikasa, N., Saito, A., Kusunoki, K., and Lilie, L.: A novel adiabatic-expansion-type cloud simulation chamber. J. Meteor. Soc. Japan, 91, 5, 687704, doi:http://dx.doi.org/10.2151/jmsj.2013-509, 2013.

Tobo, Y., DeMott, P. J., Hill, T. C. J., Prenni, A. J., Swoboda-Colberg, N. G., Franc, G. D., and Kreidenweis, S. M.: Organic matter matters for ice nuclei of agricultural soil origin, Atmos. Chem. Phys. Discuss., 14, 9705-9728, doi:10.5194/acpd-14-9705-2014, 2014.

Vali, G.: Quantitative evaluation of experimental results an the heterogeneous freezing nucleation of supercooled liquids. J. Atmos. Sci., 28, 402-409. doi:http://dx.doi.org/10.1175/1520-0469(1971)028<0402:QEOERA>2.0.CO;2, 1971. 
Welti, A., Lüönd, F., Stetzer, O., and Lohmann, U.: Influence of particle size on the ice nucleating ability of mineral dusts, Atmos. Chem. Phys., 9, 6705-6715, doi:10.5194/acp-96705-2009, 2009.

Wex, H., DeMott, P. J., Tobo, Y., Hartmann, S., Rösch, M., Clauss, T., Tomsche, L.,

1208 Niedermeier, D., and Stratmann, F.: Kaolinite particles as ice nuclei: learning from the use of 1209 different kaolinite samples and different coatings, Atmos. Chem. Phys., 14, 5529-5546, 1210 doi:10.5194/acp-14-5529-2014, 2014.

Wright, T. P. and Petters, M. D.: The role of time in heterogeneous freezing nucleation, J. Geophys. Res. Atmos., 118, 3731-3743, doi:10.1002/jgrd.50365, 2013. 